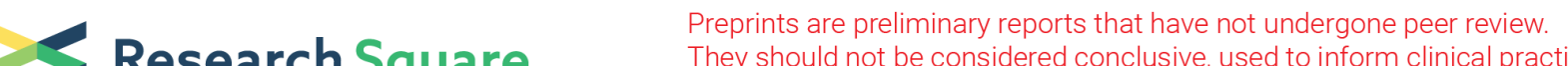 Research Square
or referenced by the media as validated information.
}

\section{Ursodeoxycholic acid breaks antitumor immunosuppression by inducing CHIP-mediated TGF- $\beta$ degradation}

\section{Ying Shen}

Zhejiang University School of Medicine

\section{Chao Lu}

Zhejiang University School of Medicine

\section{Zheng Song}

Zhejiang Cancer Hospital

\section{Chen Qiao}

Zhejiang University School of Medicine

\section{Jian Ye}

Hangzhou First People\&\#39;s Hospital, School of Medicine, Zhejiang University

Jin Chen

Hangzhou Xixi Hospital

\section{Cheng Zhang}

Zhejiang University School of Medicine

\section{Ze Ma}

Zhejiang University School of Medicine

\section{Tao Chen}

The Second Affiliated Hospital, Zhejiang University School of Medicine

\section{Xu Li}

Westlake University

Aifu Lin

Zhejiang University https://orcid.org/0000-0002-3968-3617

\section{Guo Jufeng}

Affiliated Hangzhou First People's Hospital, Zhejiang University School of Medicine

\section{Jianli Wang}

Zhejiang University School of Medicine

\section{Zhijian Cai ( $\nabla$ caizj@zju.edu.cn )}

Zhejiang University School of Medicine https://orcid.org/0000-0003-4317-2630 
Keywords: TGF- $\beta$, Ursodeoxycholic acid, CHIP, PKA, Antitumor immunity, Anti-PD-1, Anti-PD-L1

Posted Date: September 10th, 2021

DOI: https://doi.org/10.21203/rs.3.rs-845862/v1

License: (c) (1) This work is licensed under a Creative Commons Attribution 4.0 International License. Read Full License

Version of Record: A version of this preprint was published at Nature Communications on June 14th, 2022. See the published version at https://doi.org/10.1038/s41467-022-31141-6. 
Ursodeoxycholic acid breaks antitumor immunosuppression by inducing CHIP-mediated TGFdegradation

Yingying Shen ${ }^{1,12}$, Chaojie Lu ${ }^{1,12}$, Zhengbo Song ${ }^{2,12}$, Chenxiao Qiao ${ }^{1,2,11,12}$, Jiaoli Wang ${ }^{3,4}$, Jinbiao Chen ${ }^{5}$, Chengyan Zhang ${ }^{1}$, Zeyu Ma ${ }^{1}$, Tao Chen ${ }^{6}, \mathrm{Xu} \mathrm{Li}^{7}$, Aifu Lin ${ }^{8}$, Jufeng Guo ${ }^{9}$, Jianli Wang ${ }^{10,11^{*}}$, Zhijian Cai ${ }^{*}$

${ }^{1}$ Institute of Immunology, and Department of Orthopaedics of the Second Affiliated Hospital, Zhejiang University School of Medicine, Hangzhou 310009, China

${ }^{2}$ Department of Medical Oncology, Zhejiang Cancer Hospital, Hangzhou 310022, China

${ }^{3}$ Key Laboratory of Clinical Cancer Pharmacology and Toxicology Research of Zhejiang Province, Affiliated Hangzhou First People’s Hospital, Zhejiang University School of Medicine, Hangzhou 310006, China

${ }^{4}$ Zhejiang University Cancer Centre, Hangzhou 310006, China

${ }^{5}$ Department of oncology, Hangzhou Xixi Hospital, Hangzhou 310023, China

${ }^{6}$ Department of Orthopedics, Musculoskeletal Tumor Center, The Second Affiliated Hospital, Zhejiang University School of Medicine, Hangzhou, China

${ }^{7}$ School of Life Science, Westlake University, Hangzhou 310024, China

${ }^{8}$ College of Life Sciences, Zhejiang University, Hangzhou 310058, China

${ }^{9}$ Department of Breast Surgery, Affiliated Hangzhou First People's Hospital, Zhejiang University School of Medicine, 310006, Hangzhou, China

${ }^{10}$ Institute of Immunology, and Bone Marrow Transplantation Center of the First Affiliated Hospital, Zhejiang University School of Medicine, Hangzhou 310058, China

${ }^{11}$ Institute of Hematology, Zhejiang University \& Zhejiang Engineering Laboratory for Stem Cell and Immunotherapy, Hangzhou 310006, China 
${ }^{12}$ These authors contributed equally to this work.

*Correspondence to Zhijian Cai: caizj@,zju.edu.cn; Jianli Wang: jlwang@zju.edu.cn 


\section{Abstract}

Blocking TGF- $\beta$ signaling is critical to enhance antitumor immunity. However, there is still no effective TGF- $\beta$ signaling inhibitors in clinic. Here, we show that clinical medicine ursodeoxycholic acid (UDCA) phosphorylates TGF- $\beta$ at T282 site via TGR5-cAMP-PKA axis, leading to the increased binding of TGF- $\beta$ and CHIP. Then, CHIP ubiquitinates TGF- $\beta$ at K315 site, initiating p62-dependent autophagy sorting and subsequent TGF- $\beta$ degradation. By degrading TGF- $\beta$, UDCA greatly enhances antitumor immunity through restraining Treg differentiation and activation in tumor-bearing mice. In addition, UDCA synergizes with anti-PD-1 to induce stronger antitumor immunity and tumor-specific immune memory in tumor-bearing mice. Notably, UDCA also reduces TGF- $\beta$ and Tregs in peripheral blood of healthy volunteers and tumor patients. Therapy combining anti-PD-1 or anti-PD-L1 with UDCA has much better efficacy in tumor patients. Thus, our results uncover a novel mechanism for TGF- $\beta$ signaling regulation and reveal UDCA as a ready-made TGF- $\beta$ signaling inhibitor in enhancing antitumor immunity.

Key words: TGF- $\beta$; Ursodeoxycholic acid; CHIP; PKA; Antitumor immunity; Anti-PD-1; Anti-PD-L1 


\section{Introduction}

TGF- $\beta$ is a potent regulatory cytokine that binds and activates the serine/threonine kinase TGF- $\beta$ RII. Subsequently, TGF- $\beta$ RII dimerizes and activates TGF- $\beta$ RI kinase (ALK5). Then, ALK5 phosphorylates Smad2 and Smad3. Phosphorylated Smad2 and Smad3 interact with Smad4, leading to the formation of transcriptional complexes. Activation of TGF- $\beta$ signaling has profound effects on the induction of tumor immunosuppression. TGF- $\beta$ inhibits antitumor $\mathrm{CD} 4^{+}$and $\mathrm{CD} 8^{+} \mathrm{T}$ cell responses. TGF- $\beta$ can also impair T-cell activation through negative effects on antigen-presenting cells. In addition, TGF- $\beta$ is critical to induce the differentiation and proliferation of Tregs ${ }^{1,2,3}$. Thus, inhibition of TGF- $\beta$ signaling will largely improves antitumor immunity.

Inhibition of TGF- $\beta$ signaling can be achieved by a variety of mechanisms. Smad7 mediates the recruitment of Smurf1/2 and Nedd4-2 ubiquitin E3 ligases to ALK5, causing the ubiquitination degradation of $\mathrm{ALK}^{4}$. Smad7 can also recruit the phosphatase GADD34-PP1c and, in turn, dephosphorylate and inactivate ALK5 ${ }^{5}$. In addition, Smad7 forms a stable complex with ALK5, blocking the phosphorylation of $\operatorname{Smad} 2$ and $\operatorname{Smad} 3^{6} . \operatorname{Smad} 2$ and $\operatorname{Smad} 3$ can also undergo ubiquitination by Nedd41 and Smurf1 after phosphorylation by CDK8/9 and glycogen synthase kinase $3 \beta$, leading to subsequent degradation $^{7}$. In contrast to the accumulating evidence in the inhibition of TGF- $\beta$ signaling, the progress of therapies through inhibiting TGF- $\beta$ signaling is very slow ${ }^{8}$. Furthermore, whether TGF- $\beta$ can be regulated at the posttranscriptional level is unknown, causing the lack of therapeutic strategies based on direct downregulation of TGF- $\beta$ protein levels.

Immune checkpoint inhibitor (ICI) therapy, particularly antibodies blocking the programmed cell death1 (PD-1)/programmed cell death ligand-1 (PD-L1) pathway, has been a milestone achievement for tumor therapy in recent decades ${ }^{9}$. After engagement by PD-L1, PD-1 on T cells transduces inhibitory signaling 
that leads to impaired T cell activation ${ }^{10,11}$. Anti-PD-1/PD-L1 can effectively block the inhibitory signaling of T cells induced by PD-L1 expressed on cells in the tumor microenvironment (TME) ${ }^{12}$. However, many other contributors are responsible for the immunosuppression of T cells in the TME, including regulatory T cells (Tregs). Tregs, one of the major immunosuppressive cells in the TME, play critical roles in tumor progression by suppressing cytotoxic $\mathrm{CD}^{+} \mathrm{T}$-cell proliferation. It is worth noting that PD-1 deficiency accelerates Tregs' proliferation and suppressive function, which causes hyperprogressive disease in patients with anti-PD-1/PD-L1 treatments ${ }^{13}$. Given the central role of TGF- $\beta$ in Treg differentiation and functions, the combined application of anti-PD-1/PD-L1 and TGF- $\beta$ pathway inhibitors could achieve amazing antitumor effects.

Ursodeoxycholic acid (UDCA), a secondary bile acid (BA), is transformed from chenodeoxycholic acid by intestinal bacteria ${ }^{14}$. UDCA has been used in clinical practices to treat the dissolution of cholesterol gallstones, primary biliary cholangitis, and other hepatobiliary disorders for a long time ${ }^{15}$. Many studies have highlighted the antitumor properties of UDCA. UDCA can reduce the risk of colitis- and chronic liver disease-associated colorectal cancer, induce the apoptosis of various tumor cells in vitro, and inhibit the proliferation of hepatocellular carcinoma cells in vitro and in vivo ${ }^{16}$. However, the effects of UDCA on antitumor immunity are ill-defined.

Here, we report that UDCA activates PKA via the TGR5-cAMP axis and then activates PKA to phosphorylate TGF- $\beta 1$ at the T282 site. Phosphorylation of the T282 site is sufficient for TGF- $\beta 1$ to recruit the E3 ubiquitin ligase CHIP, leading to increased ubiquitination of TGF- $\beta 1$ at the K315 site. Then, ubiquitinated TGF- $\beta 1$ interacts with p62 and is sorted into autophagosomes for degradation. Therefore, UDCA greatly inhibits the differentiation and activation of Tregs and eventually attenuates the immunosuppression mediated by Tregs in tumor mice. In vivo studies show that the combination of UDCA 
and anti-PD-1 has better antitumor effects than a single treatment, which stimulates stronger antitumor immune responses and immune memory. Our data unravel a novel mechanism for the posttranslational regulation of TGF- $\beta 1$, thus providing future strategies for tumor therapy.

\section{Results}

\section{UDCA inhibits tumor growth by suppressing Treg differentiation and activation}

UDCA substantially inhibited the progression of diverse tumors, including B16-F10 murine melanoma, LLC murine Lewis lung cancer, and MC38 murine colon cancer (Fig. 1a), but showed no cytotoxicity to these cells (Supplementary Fig. 1a). Therefore, we investigated whether UDCA could affect antitumor immunity. In UDCA-treated LLC tumor-bearing mice, decreased Foxp $3^{+} \mathrm{CD}^{+} \mathrm{T}$ cells (Tregs) and increased Foxp $3^{-} \mathrm{CD} 4^{+} \mathrm{T}$ cells (Tconv) and $\mathrm{CD} 8^{+} \mathrm{T}$ cells were observed in tumor-infiltrating leukocytes (TILs) (Fig. 1b). However, CD19 ${ }^{+} \mathrm{B}$ cells, $\mathrm{MHC}-\mathrm{II}^{+} \mathrm{CD} 11 \mathrm{c}^{+}$dendritic cells, F4/80 $\mathrm{CD}^{+} 1 \mathrm{~b}^{+}$macrophages, $\mathrm{Gr}^{+} \mathrm{CD} 11 \mathrm{~b}^{+}$neutrophils and CD3-NK1.1 ${ }^{+} \mathrm{NK}$ cells remained unchanged (Supplementary Fig. 1b). UDCA could not inhibit tumor growth in NOD Prkdc ${ }^{\mathrm{scid}} \mathrm{Il}_{2 \mathrm{rg}}^{-/-}$(NSG) mice or thymus-deficient nude mice (Supplementary Fig. 1c), indicating the essential role of $\mathrm{T}$ cells in this process. The depletion of either $\mathrm{CD}^{+} \mathrm{T}$ cells or $\mathrm{CD}^{+} \mathrm{T}$ cells ablated the tumor inhibitory effects of UDCA (Supplementary Fig. 1d). Furthermore, depletion of Tregs was sufficient to eliminate the tumor inhibitory effects of UDCA (Fig. 1c), which suggested that increased Tconv and $\mathrm{CD} 8^{+} \mathrm{T}$ cells were probably caused by diminished Tregs. To confirm this, we detected $\mathrm{CD} 8^{+} \mathrm{T}$ cells or Tregs after Treg or $\mathrm{CD} 8^{+} \mathrm{T}$ cell depletion, respectively. After Treg depletion, UDCA no longer increased $\mathrm{CD} 8^{+} \mathrm{T}$ cells in TILs (Fig. 1d). However, depletion of $\mathrm{CD} 8^{+} \mathrm{T}$ cells, UDCA still reduced Tregs in TILs (Fig. 1e). Thus, UDCA improves antitumor immunity by reducing Tregs. 
Reduced Tregs might stem from decreased induction of Tregs or impaired Treg proliferation. UDCA did not affect the Ki- $67^{+}$cell proportion of Tregs (Supplementary Fig. 1e), suggesting that UDCA blunted Treg differentiation. TGF- $\beta$ plays a central role in Treg differentiation ${ }^{3,17}$. Before noticeable differences in tumor size were observed, we found that three homologous TGF- $\beta$ isoforms, TGF- $\beta 1$, TGF- $\beta 2$, and TGF- $\beta 3$, were significantly decreased in the sera and tumor tissues of UDCA-treated mice (Fig. 1f). To investigate the role of TGF- $\beta$ in the UDCA-mediated reduction in Tregs, we subcutaneously inoculated LLC tumor cells into mice deficient in TGF- $\beta$ RII $\left(T g f b r 2^{f / f} E r\right.$-cre, plus tamoxifen treatment) and then treated these mice with UDCA. We found that UDCA could not inhibit tumor growth in $T g f b r 2^{f f f} E r-c r e$ mice (Fig. 1g). In addition, UDCA did not decrease Tregs or increase Tconv and CD8 ${ }^{+} \mathrm{T}$ cells (Fig. 1h). Similar results were observed in mice deficient with $\operatorname{Smad} 3\left(\operatorname{Smad}^{-/-}\right)$, a central downstream molecule of TGF- $\beta$ signaling ${ }^{18,19}$ (Supplementary Fig. 1f, g). Therefore, UDCA reduced Tregs dependent on TGF- $\beta$.

As TGF- $\beta 1$ is also critical for Treg suppressive functions ${ }^{20}$, we examined TGF- $\beta 1$ in Tregs from TILs and found that UDCA significantly reduced it (Supplementary Fig. 2a). UDCA also decreased CTLA4, ICOS, and GITR, the key indicators for Treg suppressive functions, on Tregs from TILs (Supplementary Fig. 2b). To obtain enough Tregs for analysis of the effects of UDCA on the inhibitory functions of Tregs, we detected the features of Tregs from the spleen of tumor-bearing mice treated with UDCA. We found that UDCA also reduced spleen Tregs and their TGF- $\beta 1$, CTLA4, ICOS, and GITR (Supplementary Fig. 2c-e). Then, we evaluated the inhibitory capacity of spleen Tregs from UDCA-treated tumor mice and found that it was significantly blunted (Fig. 1i). However, UDCA did not affect the inhibitory capacity of spleen Tregs from $T g f b r 2^{f f f} E r$-cre tumor mice (Supplementary Fig. 2f). Taken together, these results indicate that UDCA enhances antitumor immunity by inhibiting the differentiation and activation of Tregs in a TGF- $\beta$-dependent manner. 

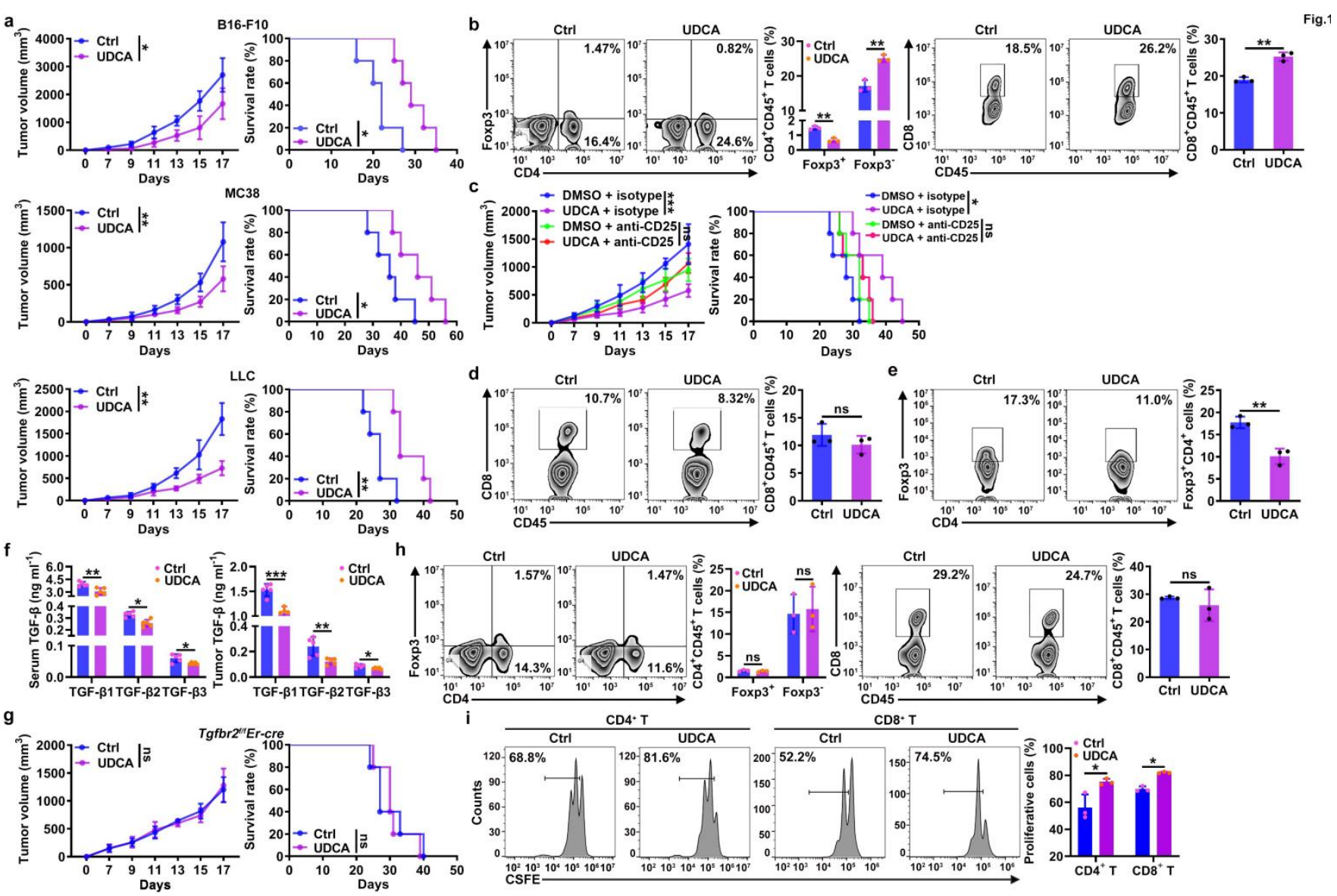

Fig. 1 | UDCA inhibits tumor growth by suppressing Treg differentiation and activation. a, b, Tumor sizes and mouse survival (a) and flow cytometric (FC) analysis of Foxp $3^{+}$or Foxp3- $3^{-} 4^{+} \mathrm{CD}^{+} 5^{+} \mathrm{T}$ cells and $\mathrm{CD}^{+} \mathrm{CD}^{+} 5^{+} \mathrm{T}$ cells in TILs on day $18(\mathbf{b})$ of B16-F10, MC38 (a) and LLC $(\mathbf{a}, \mathbf{b})$ tumor-bearing mice that received intraperitoneal (i.p.) injection with $30 \mathrm{mg} \mathrm{kg}^{-1}$ UDCA every 2 days. c-e, Tumor sizes and mouse survival (c), and $\mathrm{FC}$ analysis of $\mathrm{CD} 8^{+} \mathrm{CD} 45^{+} \mathrm{T}$ cells and Foxp $3^{+} \mathrm{CD} 4^{+} \mathrm{CD} 45^{+} \mathrm{T}$ cells in TILs on day 18 (d, e) of LLC tumor-bearing mice that received i.p. injection of $30 \mathrm{mg} \mathrm{kg}^{-1}$ UDCA every 2 days and $100 \mu \mathrm{g}$ anti-CD25 (c, d) or $40 \mu \mathrm{g}$ anti-CD8-neutralizing antibodies (anti-CD8) (e) every 3 days. f, ELISA analysis of TGF- $\beta 1$, TGF- $\beta 2$, and TGF- $\beta 3$ in sera and tumor tissues of LLC tumor-bearing mice that received i.p. injection of $30 \mathrm{mg} \mathrm{kg}^{-1}$ UDCA every 2 days on day $9 . \mathbf{g}, \mathbf{h}$, Tumor sizes and mouse survival (g) and FC analysis of Foxp $3^{+}$or Foxp3 ${ }^{-} \mathrm{CD} 4^{+} \mathrm{CD} 45^{+} \mathrm{T}$ cells and $\mathrm{CD} 8^{+} \mathrm{CD} 45^{+} \mathrm{T}$ cells in TILs on day 18 (h) of LLC tumor-bearing $T g f b r 2^{f f f} E r$-cre mice that received i.p. injection with $30 \mathrm{mg} \mathrm{kg}^{-1} \mathrm{UDCA}$ every 2 
days. $\mathbf{i}$, FC analysis of the proliferation of CFSE-labeled $\mathrm{CD}^{+}$or $\mathrm{CD}^{+} \mathrm{T}$ cells cocultured with $\mathrm{CD} 4{ }^{+} \mathrm{CD} 25^{+}$Tregs isolated from the spleen of LLC tumor-bearing mice that received i.p. injection of 30 mg kg ${ }^{-1}$ UDCA every 2 days on day 18 at a 4:1 ratio in anti-CD3 and anti-CD28-coated plates for 5 days. Representative results from three independent experiments are shown $(n=3-5) .{ }^{*} P<0.05 ; * * P<0.01$; ***P $P 0.001$ and ns, not significant (unpaired Student's $t$-test except log-rank test was used for survival rate analysis; mean and s.d.).

\section{UDCA inhibits Treg differentiation and function by decreasing TGF- $\beta$}

To further verify the role of UDCA in Treg differentiation, we differentiated naïve CD4 ${ }^{+} \mathrm{T}$ cells into Tregs by $\mathrm{T}$ cell receptor (TCR) stimulation combined with TGF- $\beta 1$ cytokine. We found that in this induction system, UDCA could not affect Treg differentiation (Supplementary Fig. 3a). However, in the absence of exogenous TGF- $\beta 1$, UDCA dose-dependently suppressed TCR stimulation-driven induction of Foxp3 $3^{+}$ Tregs and Foxp3 mRNA levels (Fig. 2a, b). Similarly, fewer Tregs were detected in TCR-stimulated naïve $\mathrm{CD}^{+} \mathrm{T}$ cells from Foxp $3^{G F P}$ transgenic mice treated with UDCA (Fig. 2c). The effects of UDCA on T cell proliferation and apoptosis were excluded (Supplementary Fig. 3b, c). In addition to UDCA, other types of BAs also suppressed TCR stimulation-driven Treg generation (Supplementary Fig. 3d). Extending this finding to antigen-specific stimulation, we found that UDCA impeded naïve $\mathrm{CD}^{+} \mathrm{T}$ cells from OT-II transgenic mice differentiated into Tregs in response to their cognate antigen $\mathrm{OVA}_{323-339}$ (Fig. 2d). These results indicate that UDCA blunts Treg generation in the absence of exogenous TGF- $\beta 1$ in vitro.

Then, we sought out how UDCA suppressed Treg differentiation and assumed that UDCA probably blunted Treg differentiation by inhibiting the endogenous generation of TGF- $\beta 1$, which is ignored in the presence of exogenous TGF- $\beta 1$. Therefore, we detected the effects of UDCA on TGF- $\beta 1$ expression in 
TCR-stimulated CD4 ${ }^{+}$T cells. UDCA substantially reduced the amount of TGF- $\beta 1$ proteins but not mRNA in TCR-stimulated $\mathrm{CD}^{+} \mathrm{T}$ cells (Fig. 2e and Supplementary Fig. 3e). In addition, UDCA reduced both latent and activated TGF- $\beta 1$ proteins in the culture supernatant of TCR-stimulated CD4 ${ }^{+}$T cells (Fig. $2 \mathrm{f}$ ). Along with the decrease in TGF- $\beta 1$, phosphorylated Smad3 protein levels were also decreased in TCRstimulated $\mathrm{CD}^{+} \mathrm{T}$ cells treated with UDCA (Supplementary Fig. 3f). Accordingly, UDCA inhibited the expression of TGF- $\beta$-inducible Smad7 and Fos genes ${ }^{21,22}$ (Supplementary Fig. 3g). However, UDCA did not affect the mRNA expression of $T g f b r 1$ and $T g f b r 2$ in TCR-stimulated CD4 ${ }^{+} \mathrm{T}$ cells (Supplementary Fig. 3h). D-mannose has been reported to induce Tregs by activating latent TGF- $\beta 1^{23}$. To exclude whether UDCA suppressed Treg induction by reducing latent TGF- $\beta 1$ activation. We induced Tregs along with latent TGF- $\beta 1$ and found that UDCA could not affect TCR stimulation-driven induction of Tregs in the presence of latent TGF- $\beta 1$ (Supplementary Fig. 3i). Thus, we concluded that UDCA blunts the activation of TGF- $\beta$ signaling by directly reducing TGF- $\beta 1$.

We next examined the role of TGF- $\beta$ in UDCA-mediated inhibition of Treg induction in vitro. TCRstimulated $\mathrm{CD}^{+} \mathrm{T}$ cells generated similar Tregs in the presence of UDCA along with ALK5 inhibitor (anti-TGF- $\beta 1$ ) (Supplementary Fig. 3j, k). Similarly, UDCA did not affect Treg induction in TCRstimulated $\mathrm{CD}^{+}{ }^{+} \mathrm{T}$ cells from $T g f b r 2^{f f f} E r$-cre mice (Supplementary Fig. 31 ). These data indicate that UDCA mediates the inhibition of Treg induction depending on TGF- $\beta$.

Cytokine cues that naïve $\mathrm{CD}^{+} \mathrm{T}$ cells encounter in vivo dictate their differentiated fate ${ }^{24}$. Tumor cells are the main source of TGF- $\beta$ in the tumor microenvironment ${ }^{25}$. We then determined whether UDCA could inhibit Treg differentiation by reducing TGF- $\beta$ from tumor cells. UDCA notably suppressed TGF- $\beta 1$, TGF- $\beta 2$, and TGF- $\beta 3$ release from OVA-expressing LLC cells (LLC-OVA) (Supplementary Fig. 3m). After coculture with LLC-OVA, numerous naïve $\mathrm{CD}^{+} \mathrm{T}$ cells from OT-II transgenic mice differentiated 
into Tregs, and UDCA significantly inhibited Treg differentiation (Fig. 2g). Moreover, when cultured in serum-free medium, UDCA still inhibited LLC-OVA-induced Tregs (Supplementary Fig. 3n). Then, we determined the effect of UDCA on the function of Tregs induced by tumor cell supernatant. In line with the in vivo results, supernatant from UDCA-treated LLC-OVA induced reduced TGF- $\beta 1$, CTLA4, ICOS, and GITR of Tregs (Supplementary Fig. 3o). Accordingly, the suppressive capacity of these Tregs was also inhibited (Supplementary Fig. 3p). Taken together, UDCA inhibits Treg differentiation and function by reducing TGF- $\beta$.
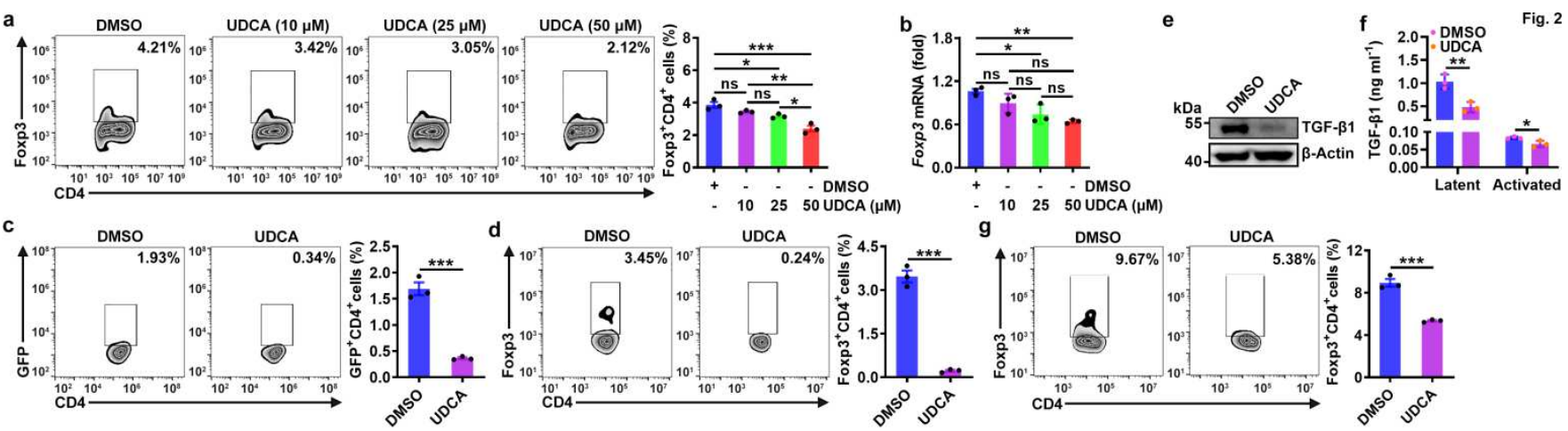

Fig. 2 UDCA inhibits Treg differentiation and function by decreasing TGF- $\beta$. $\mathbf{a}, \mathbf{b}$, FC analysis of Foxp $3^{+} \mathrm{CD} 4^{+} \mathrm{T}$ cells (a) and real-time PCR analysis of the Foxp 3 gene (b) in naïve $\mathrm{CD} 4^{+} \mathrm{T}$ cells stimulated with anti-CD3, anti-CD28, and the indicated concentration of UDCA for 4 days. c, FC analysis of $\mathrm{GFP}^{+} \mathrm{CD}^{+} \mathrm{T}$ cells in naïve $\mathrm{CD}^{+} \mathrm{T}$ cells from $F_{\text {oxp }}{ }^{G F P}$ mice stimulated with anti-CD3, anti-CD28, and $50 \mu \mathrm{M}$ UDCA for 4 days. d, FC analysis of Foxp $3^{+} \mathrm{CD}^{+} \mathrm{T}$ cells in naïve $\mathrm{CD} 4^{+} \mathrm{T}$ cells from OT-II mice stimulated with $2 \mu \mathrm{g} \mathrm{ml}^{-1} \mathrm{OVA}_{323-339}$ peptide plus T-cell depleted $\gamma$-irradiated splenic cells in the presence of $50 \mu \mathrm{M}$ UDCA for 4 days. e, f, Western blotting (IB) (e) or ELISA (f) analysis of TGF- $\beta 1$ in naïve CD4 ${ }^{+}$ T cells stimulated with anti-CD3, anti-CD28, and $50 \mu \mathrm{M}$ UDCA for $24 \mathrm{~h}(\mathbf{e})$ or in the culture supernatant (f). g, FC analysis of Foxp $3^{+} \mathrm{CD} 4^{+} \mathrm{T}$ cells in naïve $\mathrm{CD} 4^{+} \mathrm{T}$ cells from OT-II mice cocultured with LLCOVA cells in the presence of $50 \mu \mathrm{M}$ UDCA for 4 days. Representative results from three independent experiments are shown $(n=3) .{ }^{*} P<0.05 ; * * P<0.01 ; * * * P<0.001$ and ns, not significant (unpaired 
Student's $t$-test; mean and s.d.).

\section{UDCA induces p62-dependent autophagic degradation of TGF- $\beta$ via the TGR5-cAMP-PKA axis}

Next, we interrogated how UDCA reduces TGF- $\beta$. TGR 5 is a membrane receptor activated by BAs, and the farnesoid X receptor (FXR), one of the nuclear receptors, is mostly dedicated to signaling by BAs ${ }^{26}$. The role of these two receptors in the UDCA-mediated reduction in TGF- $\beta$ was examined. We found that the TGR5 agonist INT777 but not the FXR agonist INT747 decreased TGF- $\beta 1$ protein levels in CD4 ${ }^{+}$T cells and inhibited Treg differentiation (Supplementary Fig. 4a, b). Furthermore, in the presence of the TGR5 inhibitor SBI-115, UDCA no longer reduced TGF- $\beta 1$ proteins in $\mathrm{CD}^{+} \mathrm{T}$ cells and inhibited Treg differentiation (Fig. 3a, b). These results indicate that UDCA downregulates TGF- $\beta$ via TGR5. Ligation of TGR5 activates adenylate cyclase, resulting in elevation of cyclic AMP (cAMP) and subsequent activation of protein kinase A (PKA) ${ }^{26}$. UDCA treatment indeed increased cAMP and activated PKA in $\mathrm{CD}^{+} \mathrm{T}$ cells (Supplementary Fig. 4c, d). In contrast to UDCA, the adenylate cyclase inhibitor MDL12330A or the selective PKA inhibitor H89 markedly increased TGF- $\beta 1$ in $\mathrm{CD}^{+} \mathrm{T}$ cells and promoted Treg differentiation (Fig. 3c-f). In addition, MDL12330A or H89 abolished the UDCA-mediated reduction in TGF- $\beta 1$ in $\mathrm{CD}^{+} \mathrm{T}$ cells and the inhibition of Treg differentiation (Fig. 3c-f). Instead, a decrease in cAMP hydrolysis by phosphodiesterase inhibitors isobutylmethylxanthine (IBMX) or overexpression of cAMP-dependent protein kinase catalytic subunit $\alpha$ (PRKACA) was sufficient to reduce TGF- $\beta 1$ and inhibit Treg differentiation (Fig. $3 g-j$ ). These results indicate that UDCA reduces TGF- $\beta$ via the TGR5-cAMP-PKA axis.

UDCA did not change the amount of $T g f b 1$ mRNA in TCR-stimulated CD4 ${ }^{+} \mathrm{T}$ cells (Supplementary Fig. 3f). In addition, in the presence of cycloheximide (CHX), UDCA could still reduce TGF- $\beta 1$ in $\mathrm{CD}^{+}$ 
T cells (Supplementary Fig. 4e). Therefore, we hypothesized that UDCA probably affects TGF- $\beta 1$ degradation. The proteasome system and autophagy are the major protein degradation pathways. The autophagy inhibitor bafilomycin A1 (Baf-A1) but not the proteasome inhibitor MG132 markedly increased TGF- $\beta 1$ accumulation in CD4 ${ }^{+}$T cells (Fig. 3k-n), which was further confirmed in $\operatorname{Atg}^{-/-}$and $A \operatorname{tg} 5^{-/-} \mathrm{CD} 4^{+}$ T cells from Atg $3^{f / f} C D 4$-cre and $A \operatorname{tg} 5^{f / f} C D 4$-cre mice obtained by crossing $\operatorname{Atg} 3^{f / f}$ or $A \operatorname{tg} 5^{f / f}$ mice with CD4cre mice (Supplementary Fig. 4f-i). Accordingly, UDCA no longer reduced TGF- $\beta 1$ and inhibited Treg differentiation of $\mathrm{Atg}^{-/-}$or $\mathrm{Atg}^{-/-} \mathrm{CD}^{+} \mathrm{T}$ cells or Baf-A1-treated wild-type (WT) $\mathrm{CD}^{+} \mathrm{T}$ cells (Fig. 3o$\mathrm{r}$ and Supplementary Fig. 4j, k). In addition, UDCA reduced exogenous TGF- $\beta 1$ in HEK293T cells, which could also be ablated by Baf-A1 (Supplementary Fig. 41). These results indicate that UDCA promotes TGF- $\beta$ degradation via the autophagy pathway.

We next asked whether UDCA promotes TGF- $\beta$ degradation by inducing autophagy and found that UDCA failed to do so (Supplementary Fig. 5a, b). Then, we hypothesized that enhanced TGF- $\beta$ degradation by UDCA stems from increased localization of TGF- $\beta$ and autophagosomes. UDCA indeed increased the localization of TGF- $\beta 1$ with autophagosomes in TCR-stimulated $\mathrm{CD}^{+} \mathrm{T}$ and HEK293T cells (Fig. 3s and Supplementary Fig. 5c). Immunoelectron microscopy further confirmed the distribution of TGF- $\beta 1$ in autophagosomes of HEK293T cells (Fig. 3t). This effect was cAMP- and PKA-dependent because in the presence of MDL12330A and H89, UDCA no longer induced the accumulation of TGF- $\beta 1$ in autophagosomes (Supplementary Fig. 5d, e). In contrast, IBMX treatment or overexpression of PRKACA alone was sufficient to promote autophagosome localization of TGF- $\beta 1$ in $\mathrm{CD}^{+} \mathrm{T}$ cells or human fibroblast NIH-3T3 cells, respectively (Supplementary Fig. 5f, g).

Adaptor proteins, including p62, NBR1, NDP52, TAX1BP1, and Optineurin, are responsible for the sorting of proteins into autophagosomes ${ }^{27}$. We hypothesized that UDCA increases the autophagosome 
localization of TGF- $\beta$ by promoting its interaction with an adaptor protein(s). First, we screened the adaptor protein(s) that determine(s) UDCA-mediated TGF- $\beta$ degradation. Knockdown of p62 but no other adaptor proteins abrogated UDCA-mediated exogenous TGF- $\beta 1$ degradation in NIH-3T3 cells (Supplementary Fig. 5h). p62 sorts proteins into autophagosomes by directly binding to LC3B ${ }^{28}$. The proximity ligation assay (PLA) revealed that UDCA induced the interaction of TGF- $\beta 1$ and LC3B depending on p62 (Supplementary Fig. 5i). In addition, p62 silencing also eliminated UDCA-mediated TGF- $\beta 1$ degradation in $\mathrm{CD}^{+} \mathrm{T}$ cells and inhibition of Treg differentiation (Supplementary Fig. $5 \mathrm{j}$, k). Then, we examined the interaction of TGF- $\beta 1$ and p62 and the effect of UDCA on it. TGF- $\beta 1$ barely interacted with p62 while UDCA obviously induced it (Fig. 3u). Similarly, in the presence of MDL12330A and H89, UDCA could not induce the interaction of TGF- $\beta 1$ and p62 (Supplementary Fig. 51, m). In contrast, IBMX or overexpression of PRKACA notably promoted their interaction (Supplementary Fig. 5n, o). Taken together, UDCA utilizes the TGR5-cAMP-PKA axis to promote p62-dependent autophagy aggregation and subsequent degradation of TGF- $\beta 1$.
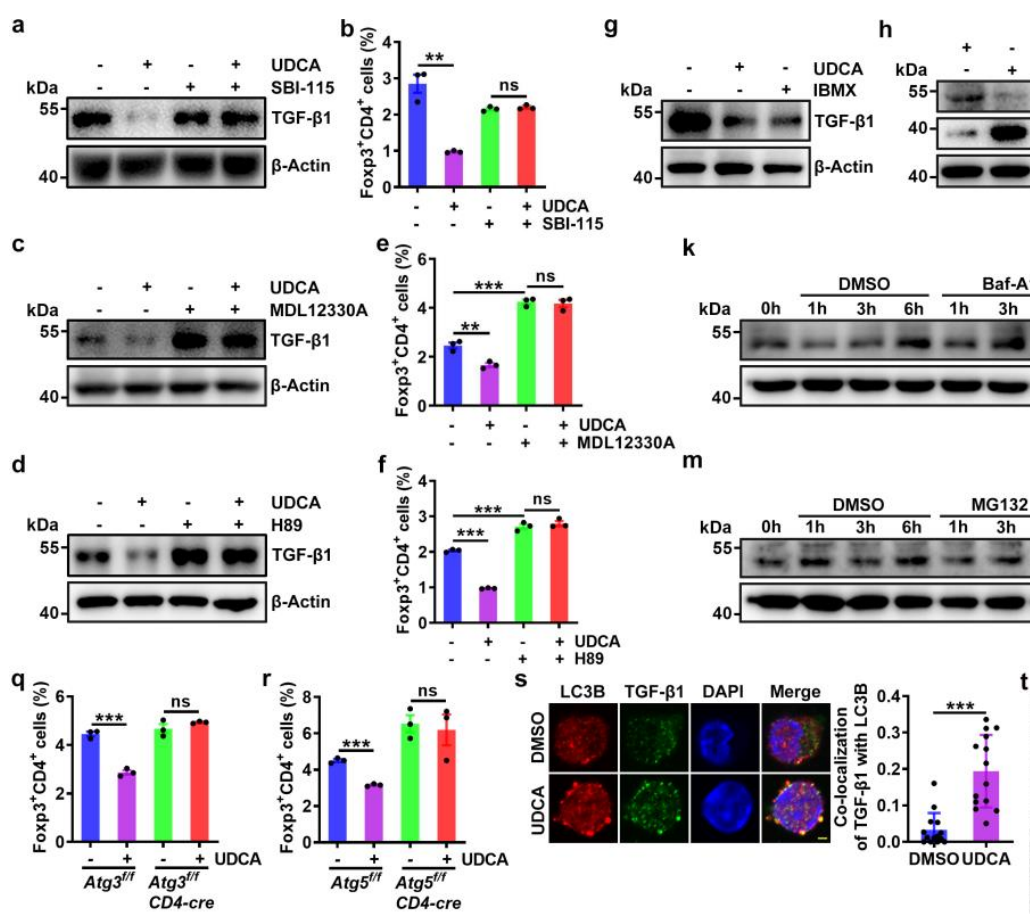

$\mathbf{k}$

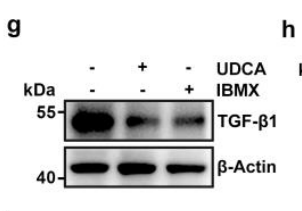

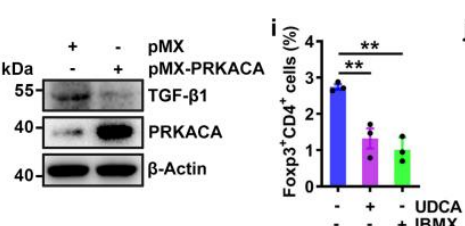
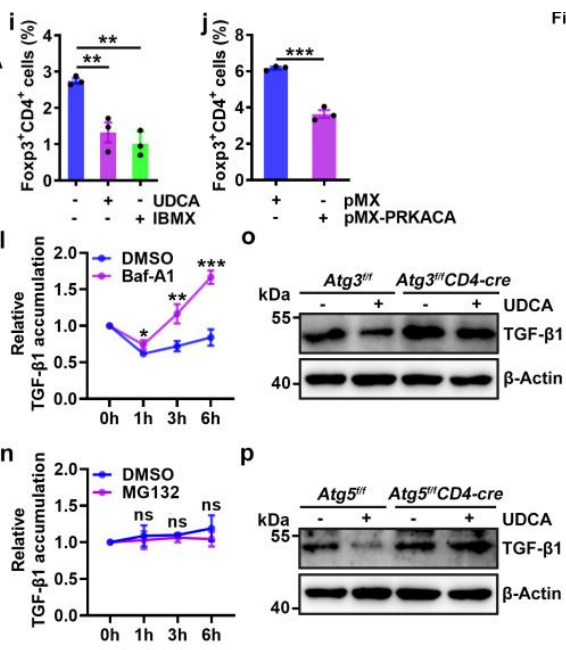
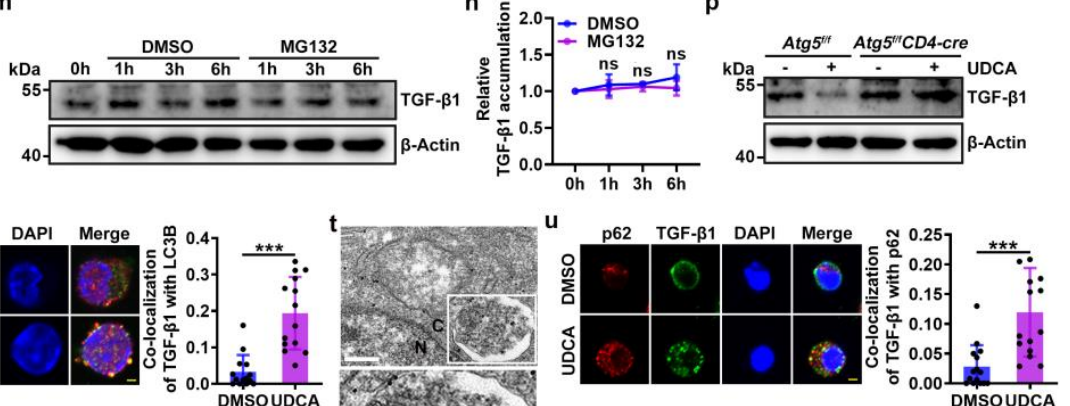
Fig. 3 | UDCA induces p62-dependent autophagic degradation of TGF- $\beta$ via the TGR5-cAMP-PKA axis. a, b, Immunoblotting (IB) analysis of TGF- $\beta 1$ (a) and FC analysis of Foxp $3^{+} \mathrm{CD} 4^{+} \mathrm{T}$ cells (b) in SBI115-treated naïve $\mathrm{CD}^{+} \mathrm{T}$ cells stimulated with anti-CD3, anti-CD28, and $50 \mu \mathrm{M}$ UDCA for $24 \mathrm{~h}(\mathrm{a})$ or 4 days (b). c-f, IB analysis of TGF- $\beta 1(\mathbf{c}, \mathbf{d})$ and $\mathrm{FC}$ analysis of Foxp $3^{+} \mathrm{CD} 4^{+} \mathrm{T}$ cells $(\mathbf{e}, \mathbf{f})$ in naïve $\mathrm{CD} 4^{+} \mathrm{T}$ cells stimulated with anti-CD3, anti-CD28, and $50 \mu \mathrm{M}$ UDCA, as well as $5 \mu \mathrm{M}$ adenylate cyclase inhibitor MDL12330A (c, e) or $2 \mu \mathrm{M}$ PKA inhibitor H89 (d, f) for $24 \mathrm{~h}(\mathbf{c}, \mathbf{d})$ or for 4 days $(\mathbf{e}, \mathbf{f})$. $\mathbf{g}-\mathbf{j}$, IB analysis of TGF- $\beta 1(\mathbf{g}, \mathbf{h})$ and FC analysis of Foxp $3^{+} \mathrm{CD} 4^{+} \mathrm{T}$ cells $(\mathbf{i}, \mathbf{j})$ in anti-CD3 and anti-CD28-stimulated naïve $\mathrm{CD}^{+} \mathrm{T}$ cells with $100 \mu \mathrm{M}$ phosphodiesterase inhibitor IBMX treatment (left) (g, i) or with PRKACA overexpression (right) $(\mathbf{h}, \mathbf{j})$ for $24 \mathrm{~h}(\mathbf{g}, \mathbf{h})$ or for 4 days (i, j). k-n, IB analysis of TGF- $\beta 1$ (k, m) and statistical analysis of TGF- $\beta 1$ stability $(\mathbf{l}, \mathbf{n})$ in naïve $C D 4^{+} \mathrm{T}$ cells stimulated with anti-CD3, anti-CD28, 10 nM Baf-A1 (k, l) or $20 \mu \mathrm{M}$ MG132 (m, n) for the indicated times. o-r, IB analysis of TGF- $\beta 1(\mathbf{o}, \mathbf{p})$ or FC analysis of Foxp $3^{+} \mathrm{CD}^{+} \mathrm{T}$ cells $(\mathbf{q}, \mathbf{r})$ in Atg3- or Atg5-deficient naïve $\mathrm{CD}^{+} \mathrm{T}$ cells stimulated with anti-CD3, anti-CD28, or $50 \mu \mathrm{M}$ UDCA for $24 \mathrm{~h}(\mathbf{o}, \mathbf{p})$ or for 4 days $(\mathbf{q}, \mathbf{r})$. s, Immunofluorescence analysis of LC3B and TGF- $\beta 1$ in naïve CD4 ${ }^{+}$T cells stimulated with anti-CD3, anti-CD28, and $50 \mu \mathrm{M}$ UDCA for $24 \mathrm{~h}$. Scale bar, $2 \mu \mathrm{m}$. t, Immunoelectron microscopy of the localization of TGF- $\beta 1$ in autophagosome of HEK293T cells. N, nucleus; C, cytoplasm. Scale bar, $500 \mathrm{~nm}$. u, Immunofluorescence analysis of p62 and TGF- $\beta 1$ in naïve $C D 4^{+} \mathrm{T}$ cells stimulated with anti-CD3, anti-CD28, and $50 \mu \mathrm{M}$ UDCA for $24 \mathrm{~h}$. Scale bar, $2 \mu \mathrm{m}$. Representative results from three independent experiments are shown $(n=3-15)$. ${ }^{*} P<0.05$; ${ }^{* *} P<0.01 ;{ }^{* * *} P<0.001$ and ns, not significant (unpaired Student's $t$-test except for one-way ANOVA followed by Newman-Keuls test in e, f; mean and s.d.).

\section{UDCA promotes K63-linked ubiquitination of TGF- $\beta 1$ at K315 by CHIP}


p62 binds to ubiquitinated proteins via a ubiquitin-associated (UBA) domain ${ }^{28}$. Full-length p62 (p62_FL) but not p62 lacking the UBA domain (p62_UBA $\Delta$ ) interacted with TGF- $\beta 1$ (Supplementary Fig. 6a). Therefore, we assumed that UDCA improves the interaction of TGF- $\beta 1$ and p62 by promoting TGF- $\beta 1$ ubiquitination. We confirmed the ubiquitination of TGF- $\beta 1$ and found that UDCA significantly promoted the total and K63-linked but not K48-linked ubiquitination of TGF- $\beta 1$ in TCR-stimulated CD4 ${ }^{+}$T cells (Fig. 4a). Furthermore, overexpression of PRKACA promoted total and K63-linked ubiquitination of TGF- $\beta 1$ in HEK293T cells (Supplementary Fig. 6b, c). These results suggest that the E3 ubiquitin ligase responsible for TGF- $\beta 1$ ubiquitination probably interacts with both TGF- $\beta 1$ and PKA. Then, we analyzed the protein interactions with TGF- $\beta 1$ and PKA by mass spectrometry. There were 14 E3 ubiquitin ligases interacting with TGF- $\beta 1$ and PKA, respectively (Supplementary Fig. 6d and Supplementary Table 1). Among these E3 ligases, 7 ligases interacted with both TGF- $\beta 1$ and PKA (Supplementary Fig. 6d). We next knocked down these 7 E3 ligases in turn and found that knockdown of CHIP but not the other 6 E3 ligases completely blocked UDCA-induced TGF- $\beta 1$ degradation in NIH-3T3 cells (Supplementary Fig. 6e). Knockdown of CHIP blocked PKA-mediated TGF- $\beta 1$ degradation in NIH-3T3 cells (Supplementary Fig. 6f). In contrast, overexpression of CHIP notably reduced the amount of TGF- $\beta 1$ protein but not mRNA in HEK293T cells (Supplementary Fig. 6g, h). Then, we confirmed the interaction of CHIP and TGF- $\beta 1$ (Fig. 4b) and found that CHIP silencing abolished UDCA-mediated inhibition of TGF- $\beta 1$ in $\mathrm{CD}^{+} \mathrm{T}$ cells (Fig. 4c). Correspondingly, UDCA-mediated inhibition of Treg induction was also eliminated by CHIP silencing (Fig. 4d). To further confirm that CHIP is an E3 ubiquitin ligase of TGF- $\beta 1$, we performed in vitro ubiquitination experiments and found that CHIP directly induced ubiquitination of TGF- $\beta 1$ (Fig. 4e). Thus, we concluded that CHIP is an E3 ubiquitin ligase of TGF- $\beta 1$.

Then, we sought to identify the ubiquitinated site(s) of TGF- $\beta 1$. We mutated 20 lysines in TGF- $\beta 1$ one 
by one and constructed vectors expressing the corresponding TGF- $\beta 1$ mutants. We found that PKAinduced ubiquitination was abolished in the TGF- $\beta 1$ K315R mutant (Supplementary Fig. 6i). In vitro ubiquitination experiments also showed that CHIP was ineffective in ubiquitinating the TGF- $\beta 1 \mathrm{~K} 315 \mathrm{R}$ mutant (Fig. 4f). Furthermore, UDCA treatment or PRKACA overexpression induced neither interaction of the TGF- $\beta 1 \mathrm{~K} 315 \mathrm{R}$ mutant and p62 nor autophagosome accumulation of the TGF- $\beta 1 \mathrm{~K} 315 \mathrm{R}$ mutant (Fig. 4g-j). Altogether, these results demonstrate that CHIP, serving as an E3 ubiquitin ligase, directly ubiquitinates TGF- $\beta 1$ at K315.

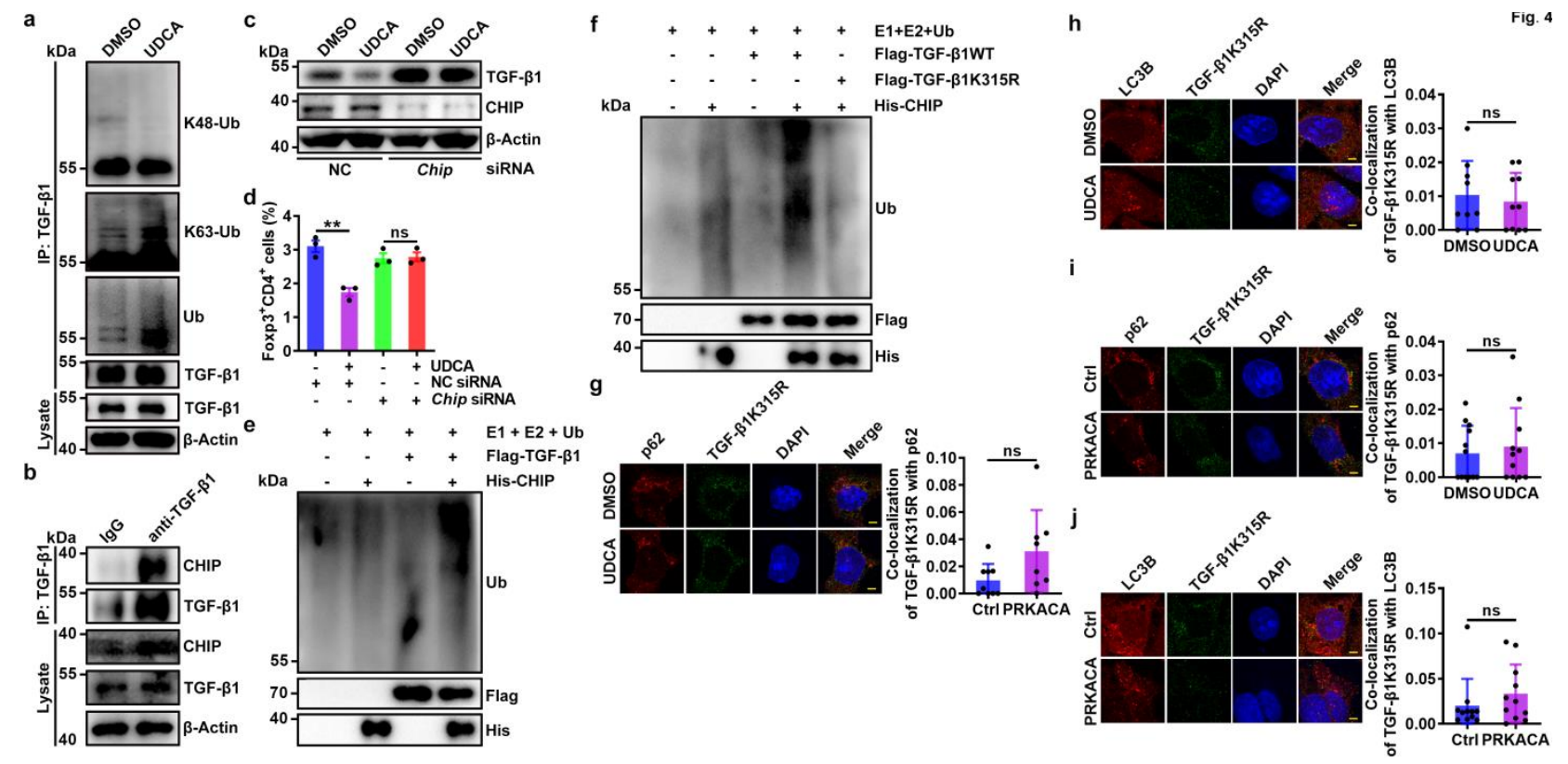

Fig. 4 | UDCA promotes K63-linked ubiquitination of TGF- $\beta 1$ at K315 by CHIP. a, IB analysis of K48-, K63-linked and total ubiquitination of TGF- $\beta 1$ in naïve CD4 ${ }^{+} \mathrm{T}$ cells stimulated with anti-CD3, anti-CD28 and $50 \mu \mathrm{M}$ UDCA for $24 \mathrm{~h}$ assessed after immunoprecipitation (IP) with anti-TGF- $\beta 1$. b, IB analysis of CHIP and TGF- $\beta 1$ in naïve $\mathrm{CD}^{+} \mathrm{T}$ cells stimulated with anti-CD3 and anti-CD28 for $24 \mathrm{~h}$ assessed after IP with anti-TGF- $\beta 1$ or IgG. $\mathbf{c}, \mathbf{d}$, IB analysis of TGF- $\beta 1$ (c) or FC analysis of Foxp $3^{+} \mathrm{CD} 4^{+}$ cells (d) in CHIP-knockdown naïve $\mathrm{CD}^{+} \mathrm{T}$ cells stimulated with anti-CD3, anti-CD28 and $50 \mu \mathrm{M}$ UDCA for $24 \mathrm{~h}$ (c) or for 4 days (d). e, f, IB analysis of TGF- $\beta 1$ ubiquitination in the presence of E1, E2, Ub, purified CHIP, and TGF- $\beta 1$ (e) or TGF- $\beta 1 \mathrm{~K} 315 \mathrm{R}$ (f). g-j, Immunofluorescence analysis of p62 and TGF- 
$\beta 1 \mathrm{~K} 315 \mathrm{R}(\mathbf{g}, \mathbf{i})$ or LC3B and TGF- $\beta 1 \mathrm{~K} 315 \mathrm{R}(\mathbf{h}, \mathbf{j})$ in NIH-3T3 cells treated with $50 \mu \mathrm{M}$ UDCA $(\mathbf{g}, \mathbf{h})$ or transfected with vectors expressing PRKACA $(\mathbf{i}, \mathbf{j})$ along with TGF- $\beta 1 \mathrm{~K} 315 \mathrm{R}$ mutant transfection for 24 h. NC, negative control. Scale bar, $2 \mu \mathrm{m}$. Representative results from three independent experiments are shown $(n=3-12) .{ }^{* *} P<0.01$ and ns, not significant (unpaired Student's $t$-test; mean and s.d.).

\section{TGF- $\beta 1$ with T282 phosphorylation by PKA binds increased CHIP}

Then, we wanted to explore how PKA promotes TGF- $\beta 1$ ubiquitination by CHIP. We found that overexpression of PRKACA did not induce Ser/Thr phosphorylation of CHIP but markedly promoted Ser/Thr phosphorylation of TGF- $\beta 1$ in HEK293T cells (Supplementary Fig. 7a, b). In addition, UDCA treatment increased Ser/Thr phosphorylation of TGF- $\beta 1$ in a PKA-dependent fashion in CD4 ${ }^{+}$T cells (Fig. 5a). The interaction of TGF- $\beta 1$ and PRKACA was also confirmed in HEK293T cells (Supplementary Fig. 7c). Then, we performed in vitro kinase assay and found that recombinant PRKACA directly phosphorylated TGF- $\beta 1$, indicating that TGF- $\beta 1$ is a direct substrate of PKA (Fig. $5 b$ ). Phosphorylation of NEK10 by PKA leads to its CHIP-mediated ubiquitination and proteolysis ${ }^{29}$. Given that UDCA treatment or overexpression of PRKACA did not increase CHIP protein levels in HEK293T cells (Supplementary Fig. 7d, e), we hypothesized that PKA-induced phosphorylation of TGF- $\beta 1$ improved its interaction with CHIP and subsequent ubiquitination. As expected, overexpression of PRKACA greatly increased the interaction of CHIP and TGF- $\beta 1$ in HEK293T cells (Supplementary Fig. 7f). In addition, UDCA treatment also increased the interaction of CHIP and TGF- $\beta 1$ via PKA in $\mathrm{CD}^{+} \mathrm{T}$ cells (Fig. $5 \mathrm{c}$ ). Then, we sought to identify phosphorylated site(s) of TGF- $\beta 1$. Mass spectrometry results revealed a phosphorylated modification at T282 of TGF- $\beta 1$ (Supplementary Table 2), and this site is conserved in mammals (Supplementary Fig. 7g). Then, we constructed a vector expressing the TGF- $\beta 1$ mutant, in which 
T282 was replaced with alanine. We confirmed that PRKACA overexpression-induced phosphorylation of TGF- $\beta 1$ was eliminated in the TGF- $\beta 1$ T282A mutant (Fig. 5d). In vitro kinase assay also showed that recombinant PRKACA hardly phosphorylated the TGF- 31 T282A mutant (Fig. 5e). A pulldown (PD) assay demonstrated that the TGF- $\beta 1$ T282A mutant barely interacted with CHIP (Fig. 5f). Correspondingly, overexpression of CHIP hardly ubiquitinated and degraded the TGF- $\beta 1$ T282A mutant (Supplementary Fig. 7h, i). In addition, in vitro ubiquitination experiments showed that recombinant CHIP could almost not ubiquitinate the TGF- $\beta 1$ T282A mutant (Fig. $5 \mathrm{~g}$ ). Altogether, PKA promotes TGF- $\beta 1$ ubiquitination by phosphorylating it at the T282 site.

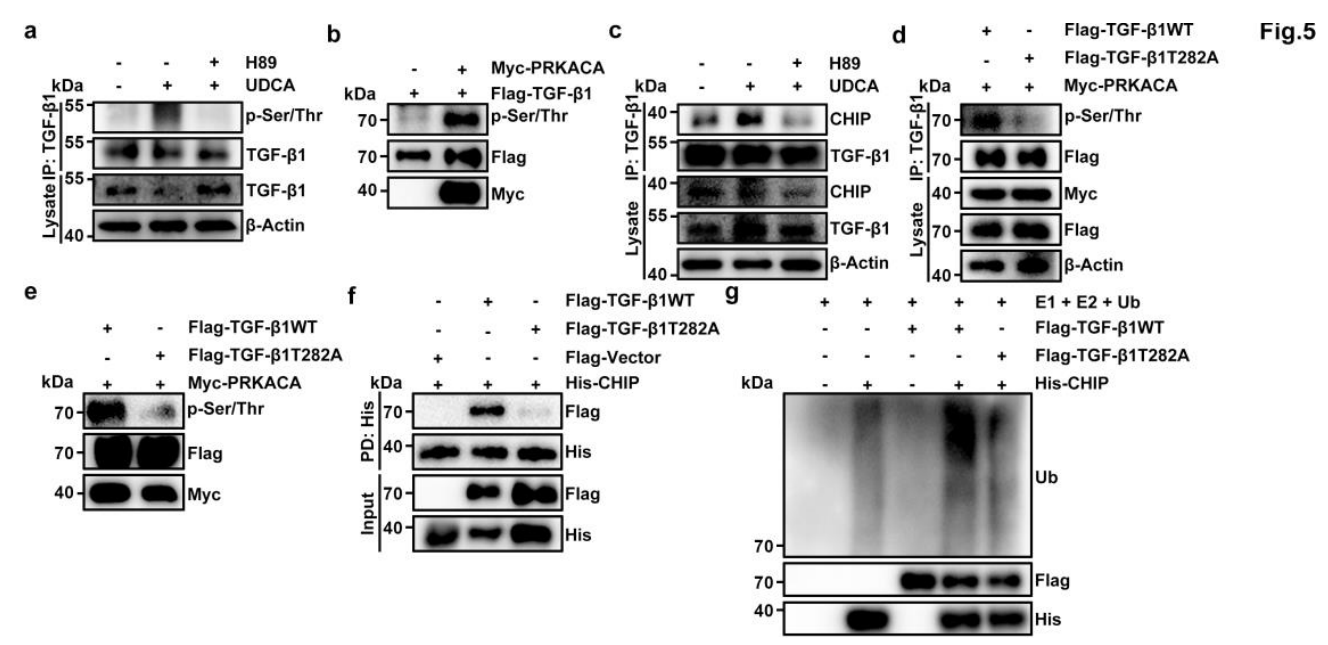

Fig. 5 | TGF- $\beta 1$ with T282 phosphorylation by PKA binds increased CHIP. a, IB analysis of pSer/Thr of TGF- $\beta 1$ in naïve CD4 ${ }^{+}$T cells stimulated with anti-CD3, anti-CD28 and $50 \mu \mathrm{M}$ UDCA with or without $2 \mu \mathrm{M}$ H89 for $24 \mathrm{~h}$ assessed after IP with anti-TGF- $\beta 1$. b, IB analysis of assay mixtures containing Flag-TGF- $\beta 1$, Myc-PRKACA and ATP that had reacted at $30^{\circ} \mathrm{C}$ for $30 \mathrm{~min}$ in vitro. c, IB analysis of CHIP and TGF- $\beta 1$ in naïve $C D 4^{+}$T cells stimulated with anti-CD3, anti-CD28 and $50 \mu \mathrm{M}$ UDCA with or without $2 \mu \mathrm{M}$ H89 for $24 \mathrm{~h}$ assessed after IP with anti-TGF- $\beta 1$. d, IB analysis of p-Ser/Thr of TGF- $\beta 1$ in HEK293 T cells transfected with vectors expressing Flag-TGF- $\beta 1$ WT, Flag-TGF- $\beta 1$ T282A, and Myc-PRKACA for 24 h. e, IB analysis of assay mixtures containing Flag-TGF- $\beta 1$ or Flag-TGF- $\beta 1$ T282A plus Myc-PRKACA 
and ATP that had reacted at $30^{\circ} \mathrm{C}$ for $30 \mathrm{~min}$ in vitro. $\mathbf{f}, \mathrm{IB}$ analysis of TGF- $\beta 1$ in the mixture of His-CHIP and Flag-TGF- $\beta 1$ WT or Flag-TGF- $\beta 1$ T282A assessed after PD with anti-His magnetic beads. g, IB analysis of TGF- $\beta 1$ ubiquitination in the presence of E1, E2, Ub, purified CHIP and TGF- $\beta 1 \mathrm{WT}$ or TGF$\beta 1 \mathrm{~T} 282 \mathrm{~A}$. Representative results from three independent experiments are shown.

\section{CHIP is negatively associated with tumor progression by reducing TGF- $\beta$}

Then, we wanted to investigate the functions of CHIP in tumor progression. First, we confirmed that UDCA TGF- $\beta 1$-dependently inhibited human Treg differentiation and activation (Fig. 6a). Then, we found that TGF- $\beta 1$, TGF- $\beta 2$, and TGF- $\beta 3$ in the supernatants of A549 human lung cancer cells and SW480 human colon cancer cells all declined after UDCA treatment, and the human Treg differentiation induced by the supernatants of both cell lines with UDCA treatment was also reduced, which was ablated by antiTGF- $\beta 1$ (Fig. 6b, c). Consistent with the reduction in TGF- $\beta 1$, CTLA4, ICOS, and GITR, the suppressive capacity of Tregs induced by A549 supernatant was also blunted by UDCA (Supplementary Fig. 8a, b). Given UDCA degradation of TGF- $\beta$ by CHIP, we analyzed the correlation between TGF- $\beta 1$ and CHIP in tumor tissues of non-small cell lung cancer (NSCLC) patients (Supplementary Table 3). Compared to paracancerous (Para-Ca) tissues, CHIP protein levels in cancerous (Ca) tissues were significantly decreased (Fig. 6d). In contrast, TGF- $\beta 1$ protein levels in tumor tissues were significantly enhanced (Fig. 6e). As expected, the protein levels of CHIP and TGF- $\beta 1$ were negatively associated (Fig. $6 \mathrm{f}$ ). In addition, the levels of phosphorylated PKA proteins were also significantly reduced in cancerous tissues and negatively correlated with TGF- $\beta 1$ levels (Fig. $6 \mathrm{~g}$, h). However, the levels of phosphorylated PKA and CHIP proteins had no correlation (Supplementary Fig. 8c). Furthermore, unfavorable progression-free survival (PFS) was obtained in non-small cell lung cancer (NSCLC) patients with lower CHIP proteins 
(Fig. 6i). These results suggest that accelerated tumor progression is related to the downregulation of CHIP and upregulation of TGF- $\beta$.

Then, we further verified the role of CHIP in tumor progression by establishing MC38 cells with CHIP knockout (MC38-Chip ${ }^{-/}$cells) (Supplementary Fig. 8d). All TGF- $\beta$ isoforms in the supernatants of MC38Chip $^{-/-}$cells were significantly higher than those in the supernatants of MC38 cells (Fig. 6j), and there was no difference in the proliferation of MC38-Chip ${ }^{-/}$and MC38 cells (Supplementary Fig. 8e). When inoculated into WT but not $T g f b r 2^{f f f} E r-c r e ~ m i c e, ~ M C 38-C h i p^{-/-}$tumors showed obvious growth priority compared to MC38 tumors (Fig. 6k, 1). Before apparent differences in the size of the tumors could be observed, there were higher TGF- $\beta 1$, TGF- $\beta 2$, and TGF- $\beta 3$ in the sera and tumor tissues of MC38-Chip ${ }^{-/-}$ tumor mice (Fig. 6m, n). In addition, increased Tregs were also detected in the TILs of MC38-Chip ${ }^{-/}$tumor mice (Fig. 6o). However, CHIP deficiency did not inhibit tumor progression in nude mice (Supplementary Fig. 8f). These results confirm that tumor CHIP promotes antitumor T cell responses by suppressing TGF$\beta$-mediated Treg differentiation. 

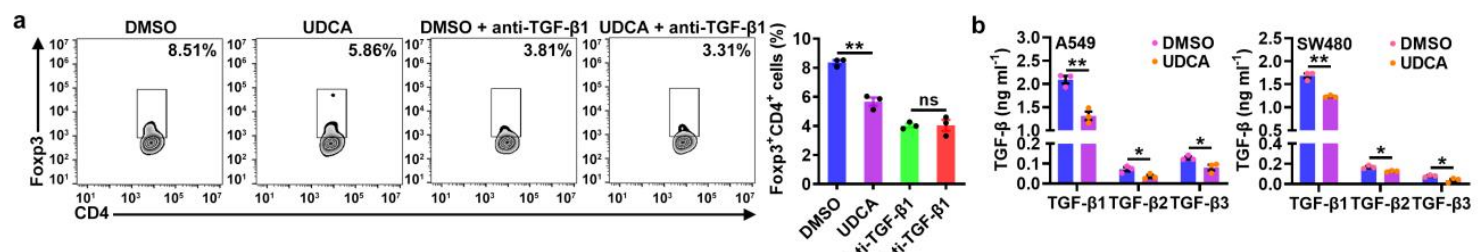

Fig. 6
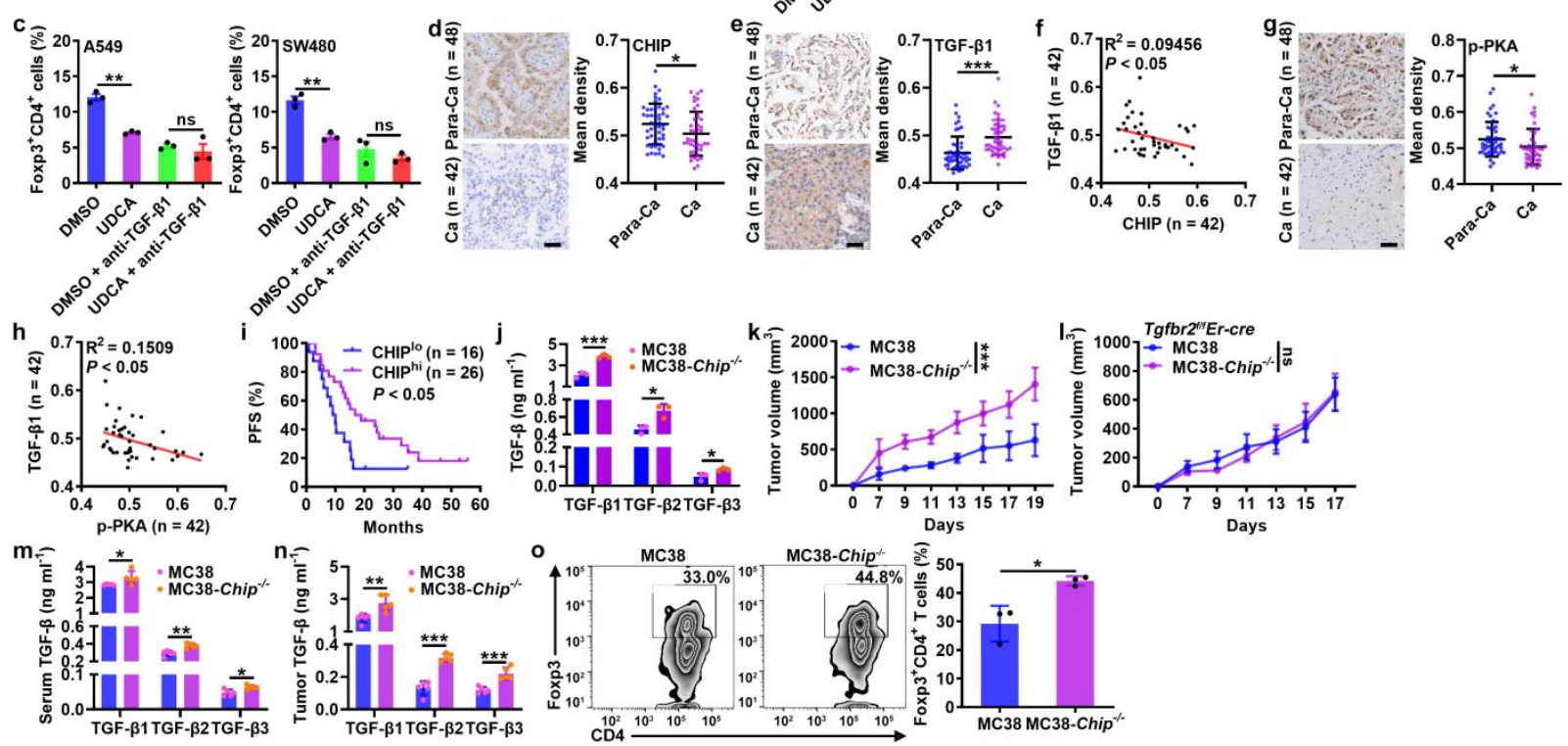

Fig. 6 | CHIP is negatively associated with tumor progression by reducing TGF- $\beta$. a, FC analysis of

Foxp $^{+} \mathrm{CD}^{+} \mathrm{T}$ cells in human naïve $\mathrm{CD} 4^{+} \mathrm{T}$ cells stimulated with anti-CD3, anti-CD28 and $50 \mu \mathrm{M}$ UDCA with or without $2 \mu \mathrm{g} \mathrm{ml}^{-1}$ anti-TGF- $\beta 1$ for 4 days. b, ELISA analysis of TGF- $\beta 1$, TGF- $\beta 2$ and TGF- $\beta 3$ proteins in supernatants of A549 and SW480 cells treated with $50 \mu \mathrm{M}$ UDCA for $24 \mathrm{~h}$. c, FC analysis of Foxp $3^{+} \mathrm{CD}^{+} \mathrm{T}$ cells in human naïve $\mathrm{CD} 4^{+} \mathrm{T}$ cells stimulated with anti-CD3 and anti-CD28 with or without $2 \mu \mathrm{g} \mathrm{ml} \mathrm{l}^{-1}$ anti-TGF- $\beta 1$ cultured in supernatants obtained in $\mathbf{b}$ for 4 days. $\mathbf{d}, \mathbf{e}$, Immunohistochemistry (IHC) analysis of CHIP (d) and TGF- $\beta 1$ (e) in Para-Ca tissues and Ca tissues of NSCLC patients. $\mathbf{f}$, Correlation between CHIP and TGF- $\beta 1$ protein levels in Ca tissues of NSCLC patients. $\mathbf{g}, \mathbf{h}$, IHC analysis of p-PKA (g) and correlation between p-PKA and TGF- $\beta 1$ protein levels (h) in Para-Ca tissues and Ca tissues of NSCLC patients (g) or in Ca tissues of NSCLC patients (h). i, PFS curve for NSCLC patients with low versus high CHIP protein levels. $\mathbf{j}$, ELISA analysis of TGF- $\beta 1$, TGF- $\beta 2$, and TGF- $\beta 3$ proteins in supernatants of MC38 and MC38-Chip ${ }^{-/-}$cells. k-o, Tumor sizes of MC38 and MC38-Chip ${ }^{-/}$tumor- 
bearing wild-type mice (k) or $T g f b r 2^{f / f} E r$-cre mice (l). ELASA analysis of TGF- $\beta 1$, TGF- $\beta 2$ and TGF- $\beta 3$ proteins in sera (m) and tumor tissues (n) and FC analysis of Foxp $3^{+} \mathrm{CD} 4^{+} \mathrm{T}$ cells in TILs (o) of MC38 and MC38-Chip ${ }^{-/}$tumor-bearing mice on day $7(\mathbf{m}, \mathbf{n})$ and on day $19(\mathbf{o})$. Representative results from three independent experiments are shown $(n=3-5)$. ${ }^{*} P<0.05 ; * * P<0.01 ; * * * P<0.001$ (unpaired Student's $t$-test in a-e, $\mathbf{g}, \mathbf{j}-\mathbf{0}$; Spearman's rank-order correlation test in $\mathbf{f}, \mathbf{h}$; or log-rank test in $\mathbf{i}$; mean and s.d.).

\section{UDCA enhances the antitumor effects of anti-PD-1}

ICI anti-PD-1 and anti-PD-L1 have shown distinguishing effects on tumor therapy ${ }^{8,30,31}$. Anti-PD-1 and anti-PD-L1 block inhibitory signaling in T cells mainly initiated by PD-L1 on tumor cells ${ }^{32,33}$. However, anti-PD-1 and anti-PD-L1 are theoretically invalid in alleviating Treg-mediated tumor immunosuppression. We suspected that UDCA and anti-PD-1 or anti-PD-L1 combinatorial therapy could break tumor immunosuppression in two ways: 1) inhibiting Treg differentiation and activation and 2) preventing PD-1 signaling of $\mathrm{T}$ cells from activation. These factors would probably significantly improve antitumor immunity. In the clinic, UDCA is orally administered to treat the dissolution of cholesterol gallstones, primary biliary cholangitis, and other hepatobiliary disorders ${ }^{15}$. Oral administration of Ursofalk (trade name of UDCA) could also notably inhibit the progression of B16-F10, LLC, and MC38 tumors (Fig. 7a). As expected, Ursofalk notably enhanced the efficacy of anti-PD-1 against LLC and MC38 tumors, resulting in complete tumor eradication (Fig. 7a). Moreover, ursofalk greatly improved the antiPD-1 efficiency in anti-PD-1-insensitive B16-F10 tumors, leading to complete tumor regression in 28.6\% of B16-F10 tumor-bearing mice (Fig. 7a). Treatment with hydroxychloroquine (HCQ), an autophagy inhibitor, no longer enhanced anti-PD-1-mediated LLC tumor inhibition (Supplementary Fig. 9a). In 
addition, Ursofalk did not improve anti-PD-1 efficacy in LLC tumor-bearing $T g f b r 2^{f / f} E r$-cre mice (Supplementary Fig. 9b). Similar results were observed in LLC tumor-bearing mice with Treg depletion (Supplementary Fig. 9c). These results demonstrate that the synergistic effects of UDCA on anti-PD-1 are autophagy-, TGF- $\beta$ - and Treg-dependent.

Then, we assessed the effect of UDCA on human anti-PD-1. When MC38 cells overexpressing human

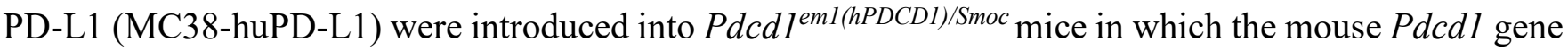
was replaced with the human $P d c d 1$ gene (Supplementary Fig. 9d), Ursofalk combined with anti-human PD-1 (SHR-1210) treatment could also completely eradicate the established tumors (Fig. 7b). Analysis of TILs before tumor disappearance showed that Ursofalk combined with SHR-1210 treatment led to a profound increase in IFN $-\gamma^{+} \mathrm{CD} 8^{+} \mathrm{T}$ cells and a decrease in Tregs among TILs (Fig. 7c). Furthermore, Ursofalk combined with SHR-1210 treatment significantly increased memory CD4 ${ }^{+}$and $\mathrm{CD} 8^{+} \mathrm{T}$ cells in peripheral blood, draining lymph nodes and spleen (Fig. 7d, e and Supplementary Fig. 9e). Correspondingly, combinatorial therapy protected the mice against tumor rechallenge from MC38-huPDL1 but not B16-F10 tumors (Fig. 7f), implying the establishment of tumor-specific immune memory.

Given the excellent safety of UDCA, we recruited 7 healthy volunteers (Supplementary Table 4) to test the effect of UDCA on human TGF- $\beta$ and Treg differentiation in vivo. Oral administration of Ursofalk once significantly decreased the serum all TGF- $\beta$ isoform levels in 5 volunteers and TGF- $\beta 1$ and TGF- $\beta 3$ levels in 6 volunteers after $24 \mathrm{~h}$ (Fig. $7 \mathrm{~g}$ ). Except for 1 volunteer with no decrease in any of the TGF- $\beta$ isoforms, the Treg proportion in the peripheral blood of the other 6 volunteers was also sharply reduced after daily oral administration of Ursofalk for 7 days (Fig. 7h). In addition, Ursofalk reduced at least one serum TGF- $\beta$ isoform levels of 7 out of 9 hepatocellular carcinoma patients and decreased serum Treg proportion of the corresponding patients (Fig. 7i, j and Supplementary Table 4). These results document 
that UDCA effectively inhibits human Treg differentiation by reducing TGF- $\beta$ in vivo. We also retrospectively analyzed the survival of 211 advanced NSCLC patients with single anti-PD-1 or anti-PDL1 treatment as second- or further-line therapy (Supplementary Table 5). During the treatment period, 7 patients also received Ursofalk treatment due to elevated bilirubin (Supplementary Table 5). Compared with the patients with anti-PD-1 or anti-PD-L1 treatment alone (median survival, 3.60 months), these 7 patients had a favorable PFS (median survival, 9.33 months) (Fig. 7k). Pancreatic cancer is insensitive to single anti-PD-1 treatment ${ }^{34,35}$. There was 1 pancreatic cancer patient who received Ursofalk treatment while using anti-PD-1 as third-line therapy (Supplementary Table 5). In this patient, we observed a notable decrease in tumor burden (Supplementary Fig. 9f). These data collectively highlight the potential of UDCA combined with anti-PD-1 or anti-PD-L1 in the establishment of powerful antitumor immunity, thereby greatly benefiting tumor therapy.
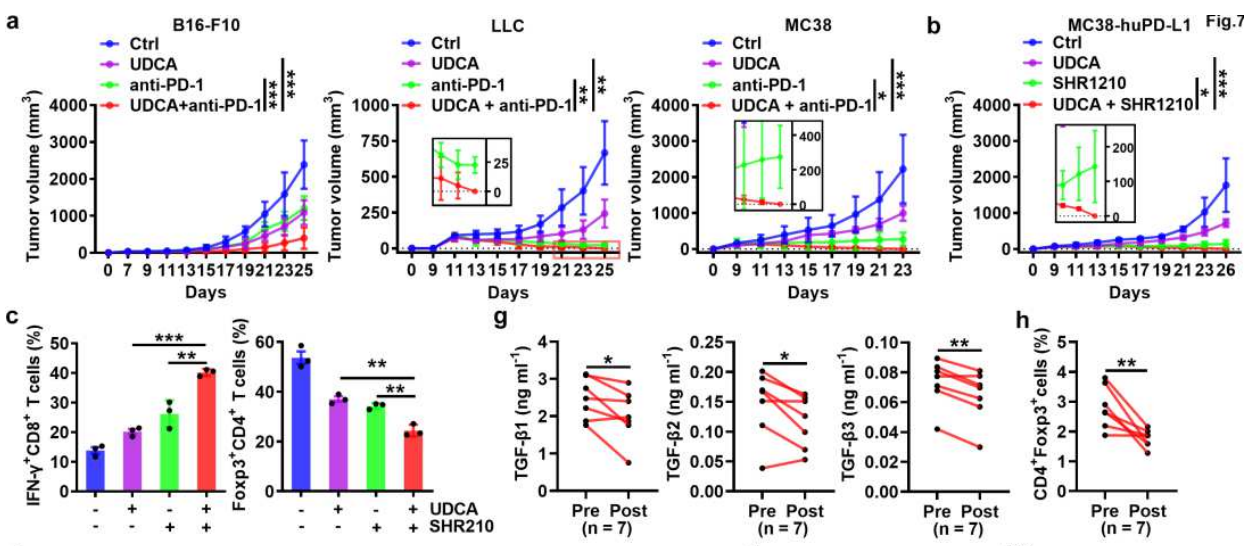

Days
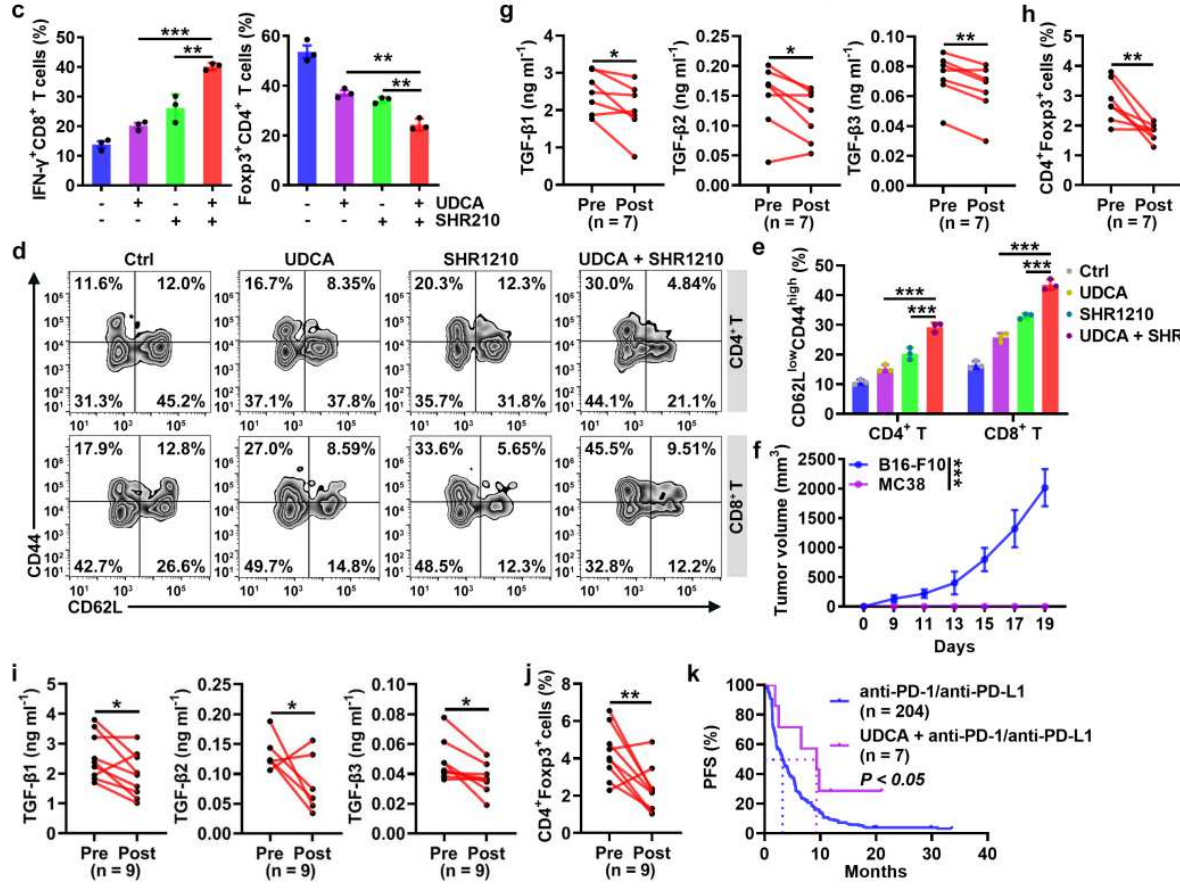

- UDCA - SHR1210

- UDCA + SHR1210 
Fig. 7 | UDCA enhances the antitumor effects of anti-PD-1. a, Tumor sizes of B16-F10, LLC or MC38 tumor-bearing mice received oral administration of $30 \mathrm{mg} \mathrm{kg}^{-1}$ Ursofalk (UDCA) every other day along with intravenous injection with $50 \mu \mathrm{g}$ anti-PD-1 every 4 days. b-e, Tumor sizes (b), FC analysis on day 18 of IFN- $\gamma^{+} \mathrm{CD} 8^{+} \mathrm{T}$ and Foxp $3^{+} \mathrm{CD} 4^{+} \mathrm{T}$ cells in TILs (c), FC (d) and statistical (e) analysis on day 33 of memory T cells in peripheral blood of MC38-huPD-L1 tumor-bearing mice received oral administration of $30 \mathrm{mg} \mathrm{kg}^{-1}$ UDCA every other day along with intravenous injection with $50 \mu \mathrm{g}$ SHR1210 every 4 days. f, Tumor sizes of tumor-free mice in $\mathbf{b}$ after rechallenging with B16-F10 or MC38-huPD-L1 cells. g-j, ELISA analysis of serum TGF- $\beta 1$, TGF- $\beta 2$ and TGF- $\beta 3$ (g, i) or FC analysis of Tregs in peripheral blood $(\mathbf{h}, \mathbf{j})$ of 7 healthy volunteers $(\mathbf{g}, \mathbf{h})$ or 9 hepatocellular carcinoma patients (i, j) before (Pre) or after (Post) oral administration of $500 \mathrm{mg}$ UDCA for $24 \mathrm{~h}(\mathbf{g}$, $\mathbf{i})$ or for 7 days $(\mathbf{h}, \mathbf{j})$. $\mathbf{k}$, PFS curve for NSCLC patients received anti-PD-1 or anti-PD-L1 with or without UDCA combinatorial treatment. Representative results from two or three independent experiments are shown (mean and s.d.). $(n=3-7) .{ }^{*} P<0.05 ; * * P<0.01$; $* * * P<0.001$ (unpaired Student's $t$-test except for log-rank test in $\mathbf{h}$; mean and s.d.).

\section{Discussion}

TGF- $\beta$ is dominant in immune suppression within the tumor microenvironment, which is central to tumor immune evasion. However, the development of therapies based on inhibiting TGF- $\beta$ signaling has achieved slow progress. The most extensively tested small molecule inhibitors target ALK5 kinase. Firstgeneration ALK5 inhibitors have failed due to overcardiac toxicity ${ }^{36}$. Though without discernable cardiac toxicities, the new type ALK5 inhibitor galunisertib only showed modest therapeutic responses to pancreatic cancer and hepatocellular carcinoma in phase II trials ${ }^{37,38,39}$. There are also anti-TGF- $\beta$ blocking pan-TGF- $\beta$ in phase I clinical trials ${ }^{8}$. However, as a type of macromolecule, the tumor 
permeability of antibodies is a huge challenge. In this study, we demonstrated that UDCA degraded both latent and activated TGF- $\beta$, leading to a decrease in total TGF- $\beta 1$, TGF- $\beta 2$, and TGF- $\beta 3$. The degraded effect of UDCA could also be observed in a variety of tumor cells and CD4 ${ }^{+} \mathrm{T}$ cells. Therefore, UDCA is a pan-TGF- $\beta$ inhibitor that reduces TGF- $\beta$ from the root. Furthermore, as one kind of choleretic, UDCA has been used in the clinic for a long time, which implies its excellent safety even for long-term application. Thus, UDCA is a ready-made TGF- $\beta$ inhibitor with high efficiency and safety.

Similar to most cytokines, TGF- $\beta$ is mainly released to exert its biological functions. Conventionally, secretory proteins are transported from the endoplasmic reticulum (ER) to the Golgi apparatus and subsequently to the plasma membrane via secretory vesicles or secretory granules ${ }^{40}$. TGF- $\beta$ in vesicles is difficult related to intracellular degradation pathways. Therefore, to date, little attention has been given to whether TGF- $\beta$ undergoes degradation and how this happens. To validate that TGF- $\beta$ was involved in intracellular degradation, we first confirmed that autophagy but not proteasome inhibitors led to the accumulation of TGF- $\beta$ in $\mathrm{CD}^{+} \mathrm{T}$ cells, suggesting autophagy-dependent degradation of TGF- $\beta$. Immunoelectron microscopy further confirmed the autophagic localization of TGF- $\beta 1$. Then, we demonstrated that TGF- $\beta$ was sorted into autophagosomes via p62. Furthermore, we verified that CHIP mediated the K63-linked ubiquitination of TGF- $\beta$ in vivo and in vitro, which is critical for autophagic sorting. Autophagy is initiated from the ER, and TGF- $\beta$ may be sorted into autophagosomes after synthesis in the ER. In addition, free ribosomes involved in TGF- $\beta$ synthesis might escape SP-mediated ER targeting, leading to direct release of TGF- $\beta$ into the cytoplasm. Then, cytoplasmic TGF- $\beta$ is regulated via the intracellular degradation pathway. The regulation of cytoplasmic TGF- $\beta$ is necessary, if cytoplasmic TGF$\beta$ can be released to function. It has been reported that the pro-forming protein gasdermin $\mathrm{D}$ mediates nonvesicle IL-1 $\beta$ secretion ${ }^{41}$. Therefore, cytoplasmic TGF- $\beta$ may also be released by a still unknown 
mechanism.

Given the important and diverse functions of TGF- $\beta$, the degradation of TGF- $\beta$ should be strictly regulated. Here, we demonstrated that UDCA-mediated ligation of TGR5 enhanced intracellular cAMP levels, resulting in activation of PKA. Subsequently, PKA phosphorylated TGF- $\beta$ at the T282 site, leading to the recruitment of CHIP. Then, CHIP ubiquitinated TGF- $\beta$, initiating autophagy sorting and subsequent degradation (Supplementary Fig. 10). Therefore, the achievement of an increase in TGF- $\beta$ needs to prevent PKA activation and reduce CHIP protein levels. In fact, according to our results, both were utilized by tumors to prevent TGF- $\beta$ degradation. We found that the protein levels of phosphorylated PKA and CHIP were significantly decreased under tumor conditions. In addition, in a tumor model with CHIP deficiency, increased TGF- $\beta$ and Tregs and accelerated tumor progression were observed. Therefore, clarification of how PKA activation is inhibited and how CHIP is downregulated could provide novel strategies to decrease TGF- $\beta$ in tumor patients, thus benefiting the reestablishment of their antitumor immunity.

ICI therapy based on anti-PD-1 and anti-PD-L1 represents a historic breakthrough in tumor immunotherapy. Although anti-PD-1 and anti-PD-L1 are effective in preventing the initiation of T cell inhibitory signals mainly induced by tumor PD-L1, theoretically, anti-PD-1 and anti-PD-L1 are invalid in relief of the tumor immunosuppressive microenvironment, in which TGF- $\beta$ plays a pivotal role. It has been reported that a bifunctional fusion protein simultaneously targeting PD-L1 and TGF- $\beta$ suppresses tumor growth and metastasis more effectively than treatment with either anti-PD-L1 antibody or TGF- $\beta$ traps alone ${ }^{42}$. Consistent with this study, our data demonstrated that UDCA combined with anti-PD-1 notably increased antitumor $\mathrm{CD}^{+} \mathrm{T}$ cell responses, decreased Tregs in TILs, and induced better tumorspecific immune memory, thus greatly improving antitumor effects. In addition, retrospective analysis of tumor patient data also suggests the priority of UDCA and anti-PD-1 combinatorial therapy. Currently, it 
cannot be asserted that UDCA and anti-PD-1 combinatorial therapy is better than the bifunctional fusion protein simultaneously targeting PD-L1 and TGF- $\beta$, which needs further clinical research. However, as an antibody-like protein, the tumor permeability of the bifunctional fusion protein is a substantial challenge. In addition, the cost of UDCA and anti-PD-1 combinatorial therapy is undoubtedly cheaper. Therefore, UDCA and anti-PD-1 combinatorial therapy hold high potential in tumor immunotherapy.

\section{Methods}

\section{Human samples}

Human lung tissue samples from NSCLC patients and Para-Ca tissues, sera of NSCLC patients and the information of 211 advanced NSCLC patients with single anti-PD-1 or anti-PD-L1 treatment were obtained from Zhejiang Cancer Hospital (IRB-2019-137). The Zhejiang Cancer Hospital Ethical Committee approved the collection of human samples (IRB-2019-137). The Ethical Committee of Zhejiang University School of Medicine approved the collection of sera from healthy volunteers (2021044). All the patients and healthy volunteers were informed of the use of their samples, and signed consent forms were obtained. The basic information from all of the patients and healthy volunteers is summarized in Supplementary Tables 3-5.

\section{Mouse and cell lines}

Female C57BL/6J mice and BALB/c-nude male mice (6-8 weeks old) were purchased from Joint Ventures Sipper BK Experimental Animal Co. (Shanghai, China). NSG mice were purchased from Biocytogen (Beijing, China). Tgfbr $2^{f f f}$ mice were kindly provided by Prof. Bin Zhou (Center for Excellence in Molecular Cell Science, Shanghai, China). Smad33-/, OT-II, Er-cre, and CD4-cre mice were purchased 
from Jackson Laboratory (Farmington, CT, USA). Foxp ${ }^{G F P}$ knock-in C57BL/6 mice were generously provided by Prof. Zhexiong Lian (South China University of Technology, Guangzhou, Guangdong, China). $\operatorname{Atg} 5^{f / f}$ mice were purchased from RIKEN BioResource Research Center (Tsukuba-shi, Japan). Atg $3^{f / f}$ mice were kindly provided by Dr. Wei Chen (Zhejiang University, Hangzhou, Zhejiang, China). $P d c d 1^{e m 1(h P D C D 1) / S m o c}$ mice with a C57BL/6J background were purchased from Nanjing Biomedical Research Institute of Nanjing University (Nanjing, Jiangsu, China). The mice were housed in a specific pathogen-free facility, and experimental protocols were approved by the Animal Care and Use Committee of Zhejiang University School of Medicine (ZJU20210045).

B16-F10, MC38, LLC, HEK293T, and NIH-3T3 cells were purchased from the American Type Culture Collection (ATCC, Manassas, VA, USA). A549 and SW480 cells were purchased from the Chinese Academy of Sciences (Shanghai, China). LLC-OVA cells were provided by Wei Yang (Southern Medical University, Guangzhou, Guangdong, China), and MC38-huPD-L1 cells were provided by Shanghai Hengrui Pharmaceutical Co., Ltd. (Shanghai, China). Murine MC38-Chip ${ }^{-/}$cells were established in our laboratory. B16-F10, MC38, 293T, NIH-3T3, and SW480 cells were cultured in DMEM supplemented with 10\% FBS; LLC and A549 cells were maintained in RPMI 1640 medium supplemented with 10\% FBS. All cells were incubated at $37^{\circ} \mathrm{C}$ in a humidified atmosphere of $5 \% \mathrm{CO}^{2}-95 \%$ air.

\section{Tumor growth experiments}

Individual C57BL/6J mice were injected subcutaneously with $1 \times 10^{6} \mathrm{LLC}$ cells, $2 \times 10^{6} \mathrm{MC} 38$ cells, or $5 \times 10^{5}$ B16-F10 cells on day 0 . The tumor-bearing mice received i.p. injection of $30 \mathrm{mg} \mathrm{kg}^{-1} \mathrm{UDCA}_{\text {(Santa }}$ Cruz Biotechnology) every 2 days. Tumor size was monitored every other day by Vernier calipers. To silence TGF- $\beta$ RII, $T g f b r 2^{f f f} E r$-cre mice received i.p. injection with tamoxifen in olive oil $\left(1 \mathrm{mg} 100 \mu \mathrm{l}^{-1}\right)$ 
on days $-10,-9,-8,0,7$ and 14 . In some experiments, nude mice, NSG mice, and $T g f b r 2^{f f f} E r$-cre mice were subcutaneously injected with $1 \times 10^{6}$ LLC cells. In vivo depletion of Tregs was achieved by injecting $100 \mu \mathrm{g}$ of anti-CD25 antibodies on days $7,10,13$, and 17 . To delete $\mathrm{CD}^{+}{ }^{+}$or $\mathrm{CD}^{+} \mathrm{T}$ cells, individual mice received i.p. injection of anti-CD4 $(120 \mu \mathrm{g})$ or anti-CD8 $(40 \mu \mathrm{g})$ on days $0,3,6,9,12$ and 15 . TILs were prepared by enzymatic digestion with $1 \mathrm{mg} \mathrm{ml}^{-1}$ collagenase IV and $0.5 \mathrm{mg} \mathrm{ml}^{-1}$ DNase I at $37^{\circ} \mathrm{C}$ for $90 \mathrm{~min}$, followed by Percoll gradient purification.

\section{In vitro $\mathrm{CD4}^{+} \mathrm{T}$ cell culture}

$\mathrm{CD}^{+} \mathrm{CD}^{2} \mathrm{~L}^{+} \mathrm{CD} 44^{-} \mathrm{CD} 25^{-}$naïve $\mathrm{CD}^{+} \mathrm{T}$ cells were purified by FACS sorting (BD FACSAria II, Becton, Dickinson and Company, Franklin Lake, NJ, USA) from splenocytes and peripheral lymph nodes and cultured at $0.4 \times 10^{6}$ cells per well in 96-well plates with plate-bound anti-CD3 $\left(2 \mu \mathrm{g} \mathrm{ml}^{-1}\right)$ and anti-CD28 $\left(2 \mu \mathrm{g} \mathrm{ml} l^{-1}\right)$ with or without latent TGF- $\beta 1\left(2 \mathrm{ng} \mathrm{ml}^{-1}\right)$ or TGF- $\beta 1\left(2 \mathrm{ng} \mathrm{ml}^{-1}\right)$ at $37^{\circ} \mathrm{C}$. In some experiments, UDCA (Sigma-Aldrich, $50 \mu \mathrm{M})$, TLCA $(50 \mu \mathrm{M}), \operatorname{CDCA}(50 \mu \mathrm{M}), \mathrm{LCA}(50 \mu \mathrm{M}), \operatorname{DCA}(50 \mu \mathrm{M}), \mathrm{GCA}(50$ $\mu \mathrm{M}), \mathrm{CA}(50 \mu \mathrm{M}), \mathrm{SBI}-115(0.25 \mu \mathrm{M}), \mathrm{H} 89(2 \mu \mathrm{M})$, IBMX (100 $\mu \mathrm{M})$, Baf-A1 (1 nM or $10 \mathrm{nM})$, MG132 (20 $\mu \mathrm{M})$, INT747 (100 $\mu \mathrm{M})$, SB431542 (S1067), CHX (S7418), MDL12330A (5 $\mu \mathrm{M})$, anti-TGF- $\beta 1(2 \mu \mathrm{g}$ $\left.\mathrm{ml}^{-1}\right)$ and INT777 $(100 \mu \mathrm{M})$ were added at the beginning of T cell culture. In addition, mouse CD4 ${ }^{+}$or $\mathrm{CD}^{+} \mathrm{T}$ cells were isolated by the mouse $\mathrm{CD} 4^{+} \mathrm{T}$ cell isolation kit or $\mathrm{CD} 8^{+} \mathrm{T}$ cell isolation kit.

For human in vitro $\mathrm{CD} 4^{+} \mathrm{T}$ cell culture, naïve $\mathrm{CD} 4{ }^{+} \mathrm{CD} 45 \mathrm{RA}^{+} \mathrm{CD} 45 \mathrm{RO}^{-} \mathrm{T}$ cells were isolated from the population of peripheral blood mononuclear cells in healthy donors by the human naïve $\mathrm{CD}^{+}{ }^{\mathrm{T}}$ Cell Isolation Kit II and stimulated with plate-bound anti-human CD3 $\left(2 \mu \mathrm{g} \mathrm{ml}^{-1}\right)$ and anti-human CD28 $(2 \mu \mathrm{g}$ $\mathrm{ml}^{-1}$ ). In addition, human Tregs or $\mathrm{CD}^{+} \mathrm{T}$ cells were isolated by the Human Regulatory $\mathrm{T}$ Cell Enrichment Kit or Human CD8 ${ }^{+}$T Cell Enrichment Kit. 


\section{Flow Cytometry}

According to the manufacturer's instructions, intranuclear staining was carried out with fixation/permeabilization buffer solution. For intracellular staining, cells were stimulated for $4 \mathrm{~h}$ at $37^{\circ} \mathrm{C}$ in a medium containing PMA $\left(50 \mathrm{ng} \mathrm{ml}^{-1}\right)$, ionomycin $\left(1 \mu \mathrm{g} \mathrm{ml}^{-1}\right)$, and brefeldin A solution, and then the cells were subjected to an intracellular staining protocol. Stained cells were analyzed on a Beckman Coulter DxFLEX flow cytometer equipped with CytExpert experiment-based software (Beckman Coulter, Inc., 250 South Kraemer Boulevard Brea, CA, USA), and data were analyzed using FlowJo software (TreeStar, Ashland, OR, USA).

\section{Measurement of cytokine levels.}

Tumor and cell culture supernatants and mouse and human serum were assayed by ELISA to measure the levels of TGF- $\beta 1$, TGF- $\beta 2$, and TGF- $\beta 3$ according to the manufacturer's instructions.

\section{Treg suppression assay}

The suppression of $\mathrm{CD}^{+}$or $\mathrm{CD}^{+} \mathrm{T}$ cell proliferation by Tregs was determined by the CFSE assay. Briefly, CFSE-labeled $\mathrm{CD}^{+}$or $\mathrm{CD}^{+} \mathrm{T}$ cells were seeded into a 96-well plate precoated with $2 \mu \mathrm{g} \mathrm{ml}{ }^{-1}$ anti-CD3 plus $2 \mu \mathrm{g} \mathrm{ml}^{-1}$ anti-CD28 with Tregs at a ratio of 4:1. Five days later, the cells were harvested, and the proliferation of $\mathrm{CD}^{+}$or $\mathrm{CD} 8^{+} \mathrm{T}$ cells was analyzed using a Beckman Coulter DxFLEX flow cytometer (Beckman Coulter, Inc.).

\section{Real-time PCR}

Total RNA was extracted using TRIzol reagent and reverse transcribed into cDNA using a cDNA synthesis 
kit according to the manufacturer's instructions. Real-time PCR was conducted using SYBR Green. The following PCR conditions were used: 1 cycle at $95{ }^{\circ} \mathrm{C}$ for $30 \mathrm{~s}$ and 40 cycles at $95{ }^{\circ} \mathrm{C}$ for $5 \mathrm{~s}$ and $60{ }^{\circ} \mathrm{C}$ for 34 s. Real-time PCR was performed with an Applied Biosystems 7500 real-time PCR system.

\section{Immunofluorescence and confocal microscopy}

$\mathrm{CD}^{+} \mathrm{T}$ cells or NIH-3T3 cells subjected to different treatments were fixed in prewarmed $4 \%$ paraformaldehyde for 30 min and permeabilized with $0.1 \%$ Triton X-100 for 10 min. After blocking with $3 \%$ bovine serum albumin and $5 \%$ goat serum, the cells were incubated at $4{ }^{\circ} \mathrm{C}$ overnight with anti-TGF$\beta 1$ and anti-LC3B or anti-p62 antibodies followed by DyLight 488- and DyLight 549-labeled secondary antibodies. Nuclei were stained with DAPI. The stained tissue sections were viewed under an Olympus FluoView FV3000 confocal microscope and imaged using an Olympus FluoView version 1.4a viewer (Olympus Corp, Tokyo, Japan). Images of the cells and sections were captured, and positive areas were analyzed.

\section{Immunogold electron microscopy}

TGF- $\beta 1$ overexpressed HEK293T cells were stimulated by $10 \mathrm{nM}$ Baf-A1 and $2.5 \mathrm{nM}$ Torin1 for $2 \mathrm{~h}$. Then, the cells were fixed in $4 \%$ paraformaldehyde with $0.1 \%$ glutaraldehyde in $0.1 \mathrm{M}$ PBS (pH 7.4) overnight at $4^{\circ} \mathrm{C}$. The fixed samples were washed and incubated in $50 \mathrm{mM}$ glycine for $5 \mathrm{~min}$ at RT. The samples were permeabilized by $0.1 \%$ saponin for $40 \mathrm{~min}$ at RT. After being washed in PBS and blocked with $0.1 \%$ BSA-c ${ }^{\mathrm{TM}}$ for $30 \mathrm{~min}$ at RT, the samples were incubated with TGF- $\beta 1$ antibody overnight at $4^{\circ} \mathrm{C}$, followed by incubation with $1.4 \mathrm{~nm}$ gold particles conjugated to anti-mouse $\mathrm{IgG}$ overnight at $4^{\circ} \mathrm{C}$. The samples were then processed as follows: post-fixation with $2.5 \%$ glutaraldehyde in $0.1 \mathrm{M}$ PBS for $4 \mathrm{~h}$ at 
$4^{\circ} \mathrm{C}$; washing in PBS, water, $0.02 \mathrm{M}$ sodium citrate buffer ( $\mathrm{pH} 7.0$ ); and treated by the silver enhancement, and thorough washing in deionized water.

Next day, the samples were washed three times in PBS for 10 min each and then fixed in $1 \%$ osmium tetroxide for $60 \mathrm{~min}$ at RT. The samples were stained in $2 \%$ uranium acetate for $30 \mathrm{~min}$ after being washed three times in PBS. Then, the samples were dehydrated through a graded ethanol series $(50 \%, 70 \%, 90 \%$ and $100 \%$ ) and $100 \%$ acetone. Next, the samples were embedded in a 1:1 solution of epon:acetone for 2 $\mathrm{h}$ at RT and a 3:1 solution of epon:acetone overnight at RT. The next day, they were placed in fresh epon for $8 \mathrm{~h}$ at $37^{\circ} \mathrm{C}$ and then embedded in epon for $72 \mathrm{~h}$ at $65^{\circ} \mathrm{C}$. Thin sections were cut and collected on grids and examined by EM (Tecnai G2 Spirit $120 \mathrm{kV}$, Thermofisher).

\section{PLA}

PLA were carried out using Duolink In Situ PLA reagents according to the manufacturer's instructions. Samples were imaged using an Olympus FluoView version 1.4a viewer (Olympus Corp). Images of the cells and sections were captured, and positive areas were analyzed.

\section{Plasmid and siRNA transfection}

HEK293T and NIH-3T3 cells were transfected with plasmids using JetPEI ${ }^{\circledR}$ Transfection Reagent according to the manufacturer's protocol.

$\mathrm{CD}^{+} \mathrm{T}$ and NIH-3T3 cells were transfected with scramble NC or targeted siRNA using TransIT-TKO Transfection Reagent according to the manufacturer's instructions. The siRNAs included murine Taxlbpl, p62, Ndp52, Nbr1, Optineurin, Huwe1, Trim32, Hectd1, Ring1, Chip, Ranbp2, Ubr5 and NC siRNA. 


\section{Retroviral infection of $\mathrm{CD}^{+} \mathrm{T}$ cells}

Retroviruses were produced by transfecting Plat-E cells with $7.5 \mu \mathrm{g}$ of pMX-Ires-gfp or pMX-PRKACA$g f p$. The cell culture medium was replaced with a fresh medium after $10 \mathrm{~h}$, and the retrovirus-containing supernatant was collected after an additional $72 \mathrm{~h}$. Naïve $\mathrm{CD} 4^{+} \mathrm{T}$ cells were first stimulated with anti-CD3 and anti-CD28 antibodies. At the $24-$ and $36-\mathrm{h}$ time points, the activated T cells were infected with $500 \mu 1$ of viral supernatant for $1 \mathrm{~h}$ by centrifugation at $1500 \times \mathrm{g}$ in the presence of $10 \mu \mathrm{g} \mathrm{ml}^{-1}$ polybrene and incubated at $37^{\circ} \mathrm{C}$ for an additional $1 \mathrm{~h}$ before the cells were removed from the viral supernatant and resuspended in the corresponding $\mathrm{T}$ cell medium for 4 days.

\section{IP and IB analysis}

Total cells were washed twice with ice-cold PBS and lysed with cell lysis buffer. Cell lysates $(20-50 \mu \mathrm{g})$ were separated by sodium dodecyl sulfate (SDS)-polyacrylamide gel electrophoresis, transferred onto PVDF membranes, and probed with a primary antibody against the target protein.

For complex co-IP, cell extracts were prepared by using lysis buffer [50 mM Tris (pH 7.4), $150 \mathrm{mM}$ $\mathrm{NaCl}, 0.5 \%$ (vol/vol) Nonidet P-40, 1 mM EDTA] supplemented with a protease inhibitor cocktail. Lysates were incubated with antibody-coupled beads for $4-6 \mathrm{~h}$ at $4{ }^{\circ} \mathrm{C}$. The immunoprecipitates were washed three times with the same buffer and subjected to IB analysis.

\section{In vitro ubiquitination assays}

An in vitro ubiquitination assay was performed as described previously ${ }^{43}$. Briefly, Flag-TGF- $\beta 1$ WT, FlagTGF- $\beta 1$ K315R, or Flag-TGF- $\beta 1$ T282A plus His-CHIP was transiently overexpressed in HEK293T cells and purified using anti-Flag magnetic beads or anti-His magnetic beads according to the manufacturer's 
protocol. Ubiquitination was analyzed with a ubiquitination kit following protocols recommended by the manufacturer.

\section{In vitro kinase assay}

An in vitro kinase assay was performed as described previously ${ }^{44}$. Briefly, Flag-TGF- $\beta 1$ WT or Flag-TGFB1T282A plus Myc-PRKACA was transiently overexpressed in HEK293T cells and purified using antiFlag magnetic beads or anti-Myc magnetic beads according to the manufacturer's protocol. The precipitated Flag-TGF- $\beta 1$, Flag-TGF- $\beta 1$ T282A, and Myc-PRKACA proteins were resuspended in $40 \mu 1$ of $1 \times$ kinase buffer supplemented with $200 \mu \mathrm{M}$ ATP. The reaction was carried out for $30 \mathrm{~min}$ at $30{ }^{\circ} \mathrm{C}$ and was terminated with $20 \mu 13 \times$ SDS sample buffer. Each sample was then boiled for 10 min at $100{ }^{\circ} \mathrm{C}$, followed by SDS-PAGE and IB analysis using the indicated antibodies.

\section{Pulldown assay}

A pulldown assay was performed as described previously ${ }^{45}$. The fusion proteins of Flag-TGF- $\beta 1 \mathrm{WT}$ or Flag-TGF- $\beta 1$ T282A plus His-CHIP were expressed in HEK293T cells and purified according to standard protocols. For the His pulldown assay, approximately $1 \mu \mathrm{g}$ of His-CHIP bound to His beads was mixed with $1 \mu \mathrm{g}$ Flag-TGF- $\beta 1 \mathrm{WT}$ or Flag-TGF- $\beta 1 \mathrm{~T} 282 \mathrm{~A}$ fusion proteins and incubated at $4{ }^{\circ} \mathrm{C}$ with gentle mixing. After overnight incubation, the beads were washed three times with cell lysis buffer, separated with SDS sample buffer, and analyzed by IB.

\section{CRISPR-Cas9-mediated depletion of CHIP}

For the depletion of CHIP in MC38 cells, a guide RNA plasmid (encoding gRNA) and Cas9-IRES-EGFP 
plasmid (encoding Cas9 and GFP) (Sigma-Aldrich) were cotransfected into MC38 cells. After cotransfection of the two plasmids into MC38 cells, GFP-positive cells were then sorted using a Beckman Coulter DxFLEX flow cytometer (Beckman Coulter, Inc.). Single sorted cells were cultured in 96-well plates. The knockout efficiency of CHIP was confirmed by IB. The selected MC38 cells demonstrating unchanged CHIP expression were used as control MC38 cells, while the MC38 cells deficient for CHIP were used as MC38-Chip ${ }^{-/}$cells.

\section{The combination of UDCA and anti-PD-1 in vivo tumor growth}

C57BL/6J mice or Tgfbr $2^{f f f} E r$-cre mice were subcutaneously injected with $1 \times 10^{6}$ LLC cells, $2 \times 10^{6}$ MC38 cells, or $5 \times 10^{5}$ B16-F10 cells on day 0 . In addition, $P d c d 1^{\text {em1 } 1(h P D C D 1) / S m o c}$ mice were subcutaneously injected with $2 \times 10^{6} \mathrm{MC} 38$-huPD-L1 cells. Then, the tumor-bearing mice received i.p. injection of UDCA (30 $\mathrm{mg} \mathrm{kg}^{-1}$ ) every 2 days along with i.p. injection of anti-mouse PD-1 (50 $\left.\mu \mathrm{g}\right)$ or anti-human PD-1 (50 $\mu \mathrm{g})$ on days 7, 11, 15 and 19. In some experiments, mice received i.p. injection of HCQ $\left(60 \mathrm{mg} \mathrm{kg}^{-1}\right)$ every other day following tumor implantation. To test the combination of UDCA and anti-PD-1 resulting in increased memory $\mathrm{CD}^{+}$and $\mathrm{CD}^{+} \mathrm{T}$ cells, $2 \times 10^{6} \mathrm{MC} 38$ cells, and $5 \times 10^{5} \mathrm{~B} 16-\mathrm{F} 10$ cells were subcutaneously injected into $P d c d 1^{e m 1(h P D C D 1) / S m o c}$ mice treated with UDCA and SHR-1210, in which MC38 tumors disappeared.

\section{Statistical analysis}

All statistical analyses were performed using GraphPad Prism 8.0 software. All data are expressed as the mean \pm s.d. An unpaired Student's $t$-test was used to compare the differences between two groups. Oneway ANOVA followed by Newman-Keuls test was used to compare the differences among multiple groups. 
The log-rank test was used for survival rate analysis, and the Spearman rank-order correlation test was used for Pearson correlation analysis. A difference was considered significant if the $P$-value was $<0.05$.

\section{References}

1. Gorelik L, Flavell RA. Immune-mediated eradication of tumors through the blockade of transforming growth factorbeta signaling in T cells. Nat Med 2001, 7(10): 1118-1122.

2. Geissmann F, Revy P, Regnault A, Lepelletier Y, Dy M, Brousse N, et al. TGF-beta 1 prevents the noncognate maturation of human dendritic Langerhans cells. J Immunol 1999, 162(8): 4567-4575.

3. Li MO, Wan YY, Sanjabi S, Robertson AKL, Flavell RA. Transforming growth factor-beta regulation of immune responses. Annu Rev Immunol 2006, 24: 99-146.

4. Kuratomi G, Komuro A, Goto K, Shinozaki M, Miyazawa K, Miyazono K, et al. NEDD4-2 (neural precursor cell expressed, developmentally down-regulated 4-2) negatively regulates TGF-ss (transforming growth factor-beta) signalling by inducing ubiquitin-mediated degradation of Smad2 and TGF-beta type I receptor. Biochem J 2005, 386: 461-470.

5. Shi W, Sun C, He B, Xiong W, Shi X, Yao D, et al. GADD34/PP1c recruited by Smad7 dephosphorylates TGF beta type I receptor. J Bone Miner Res 2003, 18: S2-S2.

6. Hayashi H, Abdollah S, Qiu YB, Cai JX, Xu YY, Grinnell BW, et al. The MAD-related protein Smad7 associates with the TGF beta receptor and functions as an antagonist of TGF beta signaling. Cell 1997, 89(7): 1165-1173.

7. Aragon E, Goerner N, Zaromytidou AI, Xi QR, Escobedo A, Massague J, et al. A Smad action turnover switch operated by WW domain readers of a phosphoserine code. Gene Dev 2011, 25(12): 1275-1288.

8. Batlle E, Massague J. Transforming Growth Factor-beta Signaling in Immunity and Cancer. Immunity 2019, 50(4): 924-940.

9. $\quad$ Sun C, Mezzadra R, Schumacher TN. Regulation and Function of the PD-L1 Checkpoint. Immunity 2018, 48(3): 434452.

10. Chemnitz JM, Parry RV, Nichols KE, June CH, Riley JL. SHP-1 and SHP-2 associate with immunoreceptor tyrosinebased switch motif of programmed death 1 upon primary human $\mathrm{T}$ cell stimulation, but only receptor ligation prevents T cell activation. J Immunol 2004, 173(2): 945-954.

11. Sheppard KA, Fitz LJ, Lee JM, Benander C, George JA, Wooters J, et al. PD-1 inhibits T-cell receptor induced phosphorylation of the ZAP70/CD3 zeta signalosome and downstream signaling to PKC theta. Febs Lett 2004, 574(13): 37-41.

12. Dong HD, Strome SE, Salomao DR, Tamura H, Hirano F, Flies DB, et al. Tumor-associated B7-H1 promotes T-cell apoptosis: A potential mechanism of immune evasion. Nat Med 2002, 8(8): 793-800.

13. Kamada T, Togashi Y, Tay C, Ha D, Sasaki A, Nakamura Y, et al. PD-1(+) regulatory T cells amplified by PD-1 blockade promote hyperprogression of cancer. Proceedings of the National Academy of Sciences of the United States of America 2019, 116(20): 9999-10008.

14. Ridlon JM, Harris SC, Bhowmik S, Kang DJ, Hylemon PB. Consequences of bile salt biotransformations by intestinal bacteria. Gut microbes 2016, 7(1): 22-39.

15. Hofmann AF, Hagey LR. Key discoveries in bile acid chemistry and biology and their clinical applications: history of the last eight decades. J Lipid Res 2014, 55(8): 1553-1595.

16. Goossens JF, Bailly C. Ursodeoxycholic acid and cancer: From chemoprevention to chemotherapy. Pharmacol 
Therapeut 2019, 203.

17. Chen WJ, Jin WW, Hardegen N, Lei KJ, Li L, Marinos N, et al. Conversion of peripheral CD4(+)CD25(-) naive T cells to $\mathrm{CD} 4(+) \mathrm{CD} 25(+)$ regulatory T cells by TGF-beta induction of transcription factor Foxp3. J Exp Med 2003, 198(12): 1875-1886.

18. Kawabata M, Miyazono K. Signal transduction of the TGF-beta superfamily by Smad proteins. J Biochem 1999, 125(1): 9-16.

19. Roberts AB, Russo A, Felici A, Flanders KC. Smad3: A key player in pathogenetic mechanisms dependent on TGFbeta. Ann Ny Acad Sci 2003, 995: 1-10.

20. Bommireddy R, Doetschman T. TGFbeta1 and Treg cells: alliance for tolerance. Trends in molecular medicine 2007, 13(11): 492-501.

21. Jung H, Lee DS, Park SK, Choi JS, Jung WK, Park WS, et al. Fucoxanthin Inhibits Myofibroblast Differentiation and Extracellular Matrix Production in Nasal Polyp-Derived Fibroblasts via Modulation of Smad-Dependent and SmadIndependent Signaling Pathways. Marine drugs 2018, 16(9).

22. Zhang Y, Feng XH, Derynck R. Smad3 and Smad4 cooperate with c-Jun/c-Fos to mediate TFG-beta-induced transcription (vol 394, pg 909, 1998). Nature 1998, 396(6710): 491-491.

23. Zhang DF, Chia C, Jiao X, Jin WW, Kasagi S, Wu RQ, et al. D-mannose induces regulatory T cells and suppresses immunopathology. Nat Med 2017, 23(9): 1036-+.

24. Murphy KM, Reiner SL. The lineage decisions of helper T cells. Nat Rev Immunol 2002, 2(12): $933-944$.

25. Teicher BA. Malignant cells, directors of the malignant process: Role of transforming growth factor-beta. Cancer Metast Rev 2001, 20(1-2): 133-143.

26. Schaap FG, Trauner M, Jansen PLM. Bile acid receptors as targets for drug development. Nat Rev Gastro Hepat 2014, 11(1): 55-67.

27. $\mathrm{Xu} \mathrm{Y,} \mathrm{Shen} \mathrm{J,} \mathrm{Ran} \mathrm{ZH.} \mathrm{Emerging} \mathrm{views} \mathrm{of} \mathrm{mitophagy} \mathrm{in} \mathrm{immunity} \mathrm{and} \mathrm{autoimmune} \mathrm{diseases.} \mathrm{Autophagy} \mathrm{2020,} \mathrm{16(1):}$ $3-17$.

28. Pankiv S, Clausen TH, Lamark T, Brech A, Bruun JA, Outzen H, et al. p62/SQSTM1 binds directly to Atg8/LC3 to facilitate degradation of ubiquitinated protein aggregates by autophagy. J Biol Chem 2007, 282(33): 24131-24145.

29. Porpora M, Sauchella S, Rinaldi L, Delle Donne R, Sepe M, Torres-Quesada O, et al. Counterregulation of cAMPdirected kinase activities controls ciliogenesis. Nat Commun 2018, 9.

30. Topalian SL, Hodi FS, Brahmer JR, Gettinger SN, Smith DC, McDermott DF, et al. Safety, Activity, and Immune Correlates of Anti-PD-1 Antibody in Cancer. New Engl J Med 2012, 366(26): 2443-2454.

31. Hodi FS, O'Day SJ, McDermott DF, Weber RW, Sosman JA, Haanen JB, et al. Improved Survival with Ipilimumab in Patients with Metastatic Melanoma. New Engl J Med 2010, 363(8): 711-723.

32. Iwai Y, Ishida M, Tanaka Y, Okazaki T, Honjo T, Minato N. Involvement of PD-L1 on tumor cells in the escape from host immune system and tumor immunotherapy by PD-L1 blockade. Proceedings of the National Academy of Sciences of the United States of America 2002, 99(19): 12293-12297.

33. Herbst RS, Soria JC, Kowanetz M, Fine GD, Hamid O, Gordon MS, et al. Predictive correlates of response to the antiPD-L1 antibody MPDL3280A in cancer patients. Nature 2014, 515(7528): 563-567.

34. Feng M, Xiong G, Cao Z, Yang G, Zheng S, Song X, et al. PD-1/PD-L1 and immunotherapy for pancreatic cancer. Cancer letters 2017, 407: 57-65.

35. Brahmer JR, Tykodi SS, Chow LQ, Hwu WJ, Topalian SL, Hwu P, et al. Safety and activity of anti-PD-L1 antibody in patients with advanced cancer. The New England journal of medicine 2012, 366(26): 2455-2465.

36. Anderton MJ, Mellor HR, Bell A, Sadler C, Pass M, Powell S, et al. Induction of heart valve lesions by small-molecule ALK5 inhibitors. Toxicologic pathology 2011, 39(6): 916-924.

37. Melisi D, Garcia-Carbonero R, Macarulla T, Pezet D, Deplanque G, Fuchs M, et al. Galunisertib plus gemcitabine vs. 
gemcitabine for first-line treatment of patients with unresectable pancreatic cancer. British journal of cancer 2018, 119(10): 1208-1214.

38. Kelley RK, Gane E, Assenat E, Siebler J, Galle PR, Merle P, et al. A Phase 2 Study of Galunisertib (TGF-beta1 Receptor Type I Inhibitor) and Sorafenib in Patients With Advanced Hepatocellular Carcinoma. Clinical and translational gastroenterology 2019, 10(7): e00056.

39. Kovacs RJ, Maldonado G, Azaro A, Fernandez MS, Romero FL, Sepulveda-Sanchez JM, et al. Cardiac Safety of TGFbeta Receptor I Kinase Inhibitor LY2157299 Monohydrate in Cancer Patients in a First-in-Human Dose Study. Cardiovascular toxicology 2015, 15(4): 309-323.

40. Viotti C. ER to Golgi-Dependent Protein Secretion: The Conventional Pathway. Methods in molecular biology 2016, 1459: 3-29.

41. Evavold CL, Ruan J, Tan Y, Xia S, Wu H, Kagan JC. The Pore-Forming Protein Gasdermin D Regulates Interleukin1 Secretion from Living Macrophages. Immunity 2018, 48(1): 35-44 e36.

42. Lan Y, Zhang D, Xu C, Hance KW, Marelli B, Qi J, et al. Enhanced preclinical antitumor activity of M7824, a bifunctional fusion protein simultaneously targeting PD-L1 and TGF-beta. Science translational medicine 2018, 10(424).

43. Chen R, Li M, Zhang Y, Zhou Q, Shu HB. The E3 ubiquitin ligase MARCH8 negatively regulates IL-1 beta-induced NF-kappa B activation by targeting the IL1RAP coreceptor for ubiquitination and degradation. Proceedings of the National Academy of Sciences of the United States of America 2012, 109(35): 14128-14133.

44. Ouyang C, Nie L, Gu MD, Wu AL, Han X, Wang XJ, et al. Transforming Growth Factor (TGF)-beta-activated Kinase 1 (TAK1) Activation Requires Phosphorylation of Serine 412 by Protein Kinase A Catalytic Subunit alpha (PKAC alpha) and X-linked Protein Kinase (PRKX). J Biol Chem 2014, 289(35): 24226-24237.

45. Xiao GT, Harhaj EW, Sun SC. NF-kappa B-inducing kinase regulates the processing of NF-kappa B2 p100. Mol Cell 2001, 7(2): 401-409.

\section{Acknowledgments}

This work was supported by the National Natural Science Foundation of China $(31970845,31770951$, 31870876, and 82001662). Major Project of Hangzhou Health Science and Technology Plan (Z20200134) and Joint Preresearch Fund for Clinical Scientific Research of Hangzhou First People's Hospital Affiliated to Zhejiang University (YYJJ2019Z07). We thank Shuangshuang Liu in the Core Facilities, Zhejiang University School of Medicine, for technical support for the immunofluorescence analysis. We thank Chenyu Yang in the Center of Cryo-Electron Microscopy (CCEM), Zhejiang University, for her technical assistance with Transmission Electron Mmicroscopy. We thank the Key Laboratory of Immunity and Inflammatory Diseases of Zhejiang Province for the support. 


\section{Supplementary Files}

This is a list of supplementary files associated with this preprint. Click to download.

- SupplementaryTable1.xlsx

- SupplementaryTable2.xlsx

- SupplementaryTable34.docx

- SupplementaryTable5.xlsx

- SupplementaryTable67.docx

- SupplementaryFigures.pdf 